\title{
La "infodemia" en la crisis del coronavirus: Análisis de desinformaciones en España y Latinoamérica
}

\author{
Cristina López-Pujalte*, María Victoria Nuño-Moral* \\ * Departamento de Información y Comunicación. Universidad de Extremadura \\ Correo-e: cloppuj@unex.es | ORCID iD: https://orcid.org/0000-0002-6210-1806 \\ Correo-e: mvnunmor@unex.es | ORCID iD: https://orcid.org/0000-0002-5447-4813
}

Recibido: 15-06-2020; 2a versión: 08-07-2020; Aceptado: 10-07-2020.

Cómo citar este artículo/Citation: López-Pujalte, C.; Nuño-Moral, M. V. (2020). La "infodemia" en la crisis del coronavirus: Análisis de desinformaciones en España y Latinoamérica. Revista Española de Documentación Científica, 43 (3), e274. https:// doi.org/10.3989/redc.2020.3.1807

Resumen: En este trabajo se analizan las desinformaciones difundidas sobre el coronavirus en España y Latinoamérica en el periodo comprendido entre el 23/01/2020 y el 03/05/2020; se estudian cuantitativamente los siguientes datos: volumen de desinformación por país, la línea de evolución temporal, tipo de desinformación, canal de difusión, las fuentes, y redes de circulación de bulos entre distintos países. En el caso de España, se examina también la correlación en la producción de desinformaciones con la evolución de la pandemia, y las tendencias de búsquedas en internet sobre el coronavirus.

Los resultados muestran claramente que la evolución de la pandemia influye en la propagación de los bulos, disparándose estos en momentos críticos como la declaración de pandemia por parte de la OMS y, en el caso de España, en los momentos de mayor tasa de crecimiento de la curva, al tiempo que las búsquedas sobre el tema alcanzan su máxima popularidad.

Palabras clave: Coronavirus; Pandemia; "Infodemia"; Desinformación; Verificación de datos; Medios de comunicación; Redes Sociales; Tendencias de búsquedas; Latinoamérica; España.

\section{"Infodemic" in the coronavirus crisis: Disinformation analysis in Spain and Latin America}

Abstract: This paper analyzes the spreaded disinformation about the coronavirus in Spain and Latin America in the 01/23/2020-05/03/2020 period. A quantitative analysis of the following variables has been carried out: volume of disinformation by country (as well as its over time evolution), type of disinformation, channel of dissemination, sources of disinformation and misleading circulation networks between countries. In the case of Spain, the correlation between disinformation production and pandemic evolution and trends searches about coronavirus issues has also been studied. The results clearly show that the evolution of the pandemic influences the propagation of hoaxes, triggered at critical moments such as the pandemic declaration made by the WHO. In the case of Spain, the higher growth rate of the disinformation curve matches the higher number of searches on the subject.

Keywords: Coronavirus; Pandemic; "Infodemic"; Disinformation; Fact-checking; Media; Social media; Search trends; Latin America; Spain.

Copyright: (c) 2020 CSIC. Este es un artículo de acceso abierto distribuido bajo los términos de la licencia de uso y distribución Creative Commons Reconocimiento 4.0 Internacional (CC BY 4.0). 


\section{INTRODUCCIÓN}

La Organización Mundial de la Salud (OMS) Ileva ya tiempo alertando de la "infodemia", entendiendo ésta como una sobrecarga excesiva de información, cierta o no, que dificulta que las personas encuentren fuentes de confianza e información fidedigna cuando la necesitan, y generalmente genera inquietud y confusión en la población e impide tomar decisiones correctas (OPS, 2020). Pero es un hecho que la actual crisis del coronavirus ha disparado la transmisión de bulos, desinformaciones o noticias falsas (fake news).

Hay que ser conscientes de que esta epidemia global de desinformación, que está propagándose rápidamente por las plataformas de redes sociales y otros canales, plantea un serio problema de salud pública (Zarocostas, 2020).

En un artículo publicado en el periódico El País el pasado 18 de febrero, se subraya que el coronavirus se está extendiendo por todo el mundo a una velocidad vertiginosa, pero todavía es mayor la velocidad a la que se expande la desinformación sobre él. Esto, a su vez, influye negativamente en la pandemia, ya que esta "infodemia" obstaculiza las medidas de contención del brote al generar confusión, inquietud, temor y división que nos impiden centrarnos en hacerle frente. En palabras del director general de la OMS, Tedros Adhanom, "la evolución del brote del coronavirus dependerá de la medida en que se haga llegar la información correcta a la gente que la necesita".

El grado de desinformación ha ido aumentando conforme el coronavirus se extendía a nivel mundial, a pesar de los esfuerzos de Google y redes sociales como Facebook y Twitter para limitar su difusión (Pérez-Dasilva y otros, 2020).

No cabe duda que es primordial luchar contra la desinformación, y más en momentos clave como éste. Con ese fin se creó en septiembre del 2015 la Red Internacional de Verificación de Datos, más conocida por sus siglas en inglés IFCN (International Fact-Checking Network), Unidad del instituto americano con sede en Florida, Poynter Institute, que tiene por objeto unir a periodistas para luchar contra los bulos y noticias falsas en todo el mundo. La IFCN actualmente trabaja en el mantenimiento de una base de datos de desinformaciones generadas sobre el coronavirus (CoronaVirusFacts/DatosCoronaVirus Alliance Database) en la que participan chequeadores de más de setenta países e incluye artículos publicados en, al menos, cuarenta idiomas.

Asimismo, a raíz de un proyecto colaborativo de verificación de noticias en Latinoamérica
(Latam Chequea) creado en 2014 y coordinado por la organización argentina Chequeado, se ha generado una plataforma de desinformaciones sobre el coronavirus (Latam Chequea - Coronavirus) en la que participan treinta y cinco organizaciones analizando las desinformaciones de dieciséis países latinoamericanos y España, utilizando como base la información en idioma español de la base de datos global de la IFCN anteriormente mencionada.

Por su parte, Google ha creado una alerta sobre el coronavirus, COVID-19 SOS Alerts, inicialmente en las seis lenguas oficiales de Naciones Unidas pero la está expandiendo también a otros idiomas; la idea es que en las búsquedas sobre el tema la primera información que reciba el público provenga de la página web y redes sociales de la OMS y otras fuentes autorizadas, para luchar de esta forma contra la propagación de la desinformación. Y también desde Google News Initiative ofrecen herramientas y recursos dirigidos a periodistas para informar durante esta crisis como, por ejemplo, tendencias de búsqueda sobre el coronavirus con Google Trends, herramientas para la verificación de datos mediante Google Fact Check Tools y una herramienta de análisis de imágenes para identificar fotografías manipuladas, Assembler.

Desde la OMS, inmediatamente después de que el Covid-19 fuese declarado emergencia de salud pública de ámbito internacional (OMS, 2020a), la organización lanzó una nueva plataforma de información, WHO Information Network for Epidemics (EPI-WIN).

Y, en las últimas semanas, la ONU (2020) anuncia el 21 de mayo una iniciativa mundial, Verified (https://www.shareverified.com/es), contra la desinformación generada en torno al coronavirus y cuyo objetivo es frenar la pandemia paralela de la desinformación y propagar información científica y veraz que proteja a la sociedad.

Dada la importancia que tiene la "infodemia" en la actual crisis sanitaria, el presente trabajo pretende analizar las noticias falsas vertidas sobre el coronavirus que nos desbordan a diario, en concreto las que circulan en España y América Latina, utilizando para ello la herramienta Latam Chequea - Coronavirus, realizando un análisis cuantitativo de las principales variables (volumen de noticias falsas por país, tipos de desinformación, canales, fuentes, etc.) y comparando, en el caso de España, su evolución tanto con la curva de la pandemia como con las tendencias de búsqueda en internet, ya que sabemos que estos bulos tienen un efecto directo y perjudicial sobre la población. 


\section{MARCO TEÓRICO}

Sylvie Briand, directora de Gestión de Riesgos Infecciosos del Programa de Emergencias Sanitarias de la OMS y artífice de la estrategia de la organización para contrarrestar el riesgo de "infodemia", declaró a The Lancet: "Sabemos que cada brote estará acompañado de una especie de tsunami de información, pero también dentro de esta información siempre tienes información errónea, rumores, etc." (Zarocostas, 2020). En realidad, siempre ha pasado esto. La diferencia ahora, en la era digital, es que el fenómeno se amplifica hasta niveles insospechados, y se propaga a gran velocidad y a nivel mundial a través de las redes sociales. Tal como Briand indica "...lo que está en juego durante un brote es asegurarte de que las personas hagan lo correcto para controlar la enfermedad o para mitigar su impacto. Por lo tanto, no se trata sólo de información para garantizar que las personas estén informadas; también se asegura de que las personas estén informadas para actuar adecuadamente".

El término "infodemia" hace referencia a una situación de miedo e inseguridad en la que la difusión de información falsa se ha generalizado (Pérez-Dasilva y otros, 2020).

En las últimas décadas con la consolidación de las tecnologías digitales, el sistema mediático ha experimentado numerosas transformaciones; nos encontramos con un sistema saturado de noticias donde informarse de manera adecuada no es sencillo debido, entre otros factores, a la desinformación y la desconfianza hacia los medios, a veces demasiado politizados (Casero-Ripollés, 2020).

Sin lugar a duda, la desinformación en los medios sociales es un tema urgente, y más aún en el campo de la salud (Ghenai y Mejova, 2018). En su trabajo, los autores realizan un estudio sobre la desinformación en temas de salud propagada por las redes sociales que publican información cuestionable $\mathrm{y}$, en particular, promueven tratamientos y medicamentos alternativos contra el cáncer que han demostrado ser ineficaces, lo cual puede constituir un peligro para la salud pública. $Y$ en medio de la creciente carga de la pandemia, hay emergencias paralelas que deben abordarse simultáneamente como es la proliferación de medicamentos falsos, noticias falsas y desinformación de medicamentos en torno a Covid-19 (Erku y otros, 2020). Por último, Wang y otros (2019) realizan una revisión sistemática de la literatura sobre la difusión de desinformación relacionada con la salud en las redes sociales, en la que los temas más ampliamente estudiados que involucran información errónea se relacionan con la vacunación, el virus del Ébola y el virus del Zika, aunque también se mencionan otros, como la nutrición, el cáncer, la fluoración del agua y el tabaquismo.

Por otro lado, las fake news sobre el brote de coronavirus pueden llevar, incluso, a provocar a su vez brotes de xenofobia, en concreto hacia pacientes y visitantes chinos, como ocurrió el 24 de enero de 2020; la información errónea de que "los pasajeros chinos de Wuhan con fiebre se deslizaron a través de la cuarentena en el Aeropuerto Internacional de Kansai" se difundió a través de múltiples canales de redes sociales, y aunque el aeropuerto internacional de Kansai lo negó rápidamente, la discriminación contra los chinos fue generalizada en Japón y el hastagh \#ChineseDon'tComeToJapan se convirtió en tendencia en Twitter (Shimizu, 2020).

A las pocas semanas de la aparición del Covid-19 en China, los rumores engañosos y las teorías de conspiración sobre su origen circularon por el mundo junto con el alarmismo, el racismo y la compra masiva de mascarillas; todo estrechamente vinculado a los nuevos ecosistemas "infomedia" del siglo XXI marcado por las redes sociales. No solo el virus se propagó muy rápidamente, sino que también la desinformación sobre el brote y, por tanto, el pánico entre la población (Depoux y otros, 2020).

Ante este panorama, la comunicación científica y la transparencia son factores clave para limitar los rumores, la desinformación y las falsas esperanzas para los pacientes (Simon, 2020). En un estudio realizado en Alemania, los autores destacan que las autoridades de salud pública consideran que la comunicación es una parte crucial de las estrategias de prevención y control de enfermedades infecciosas. La comunicación se vuelve aún más importante durante las crisis de salud pública, como las pandemias, y la población reacciona ante ellas con miedo debido a la falta de información o una cobertura mediática sensacionalista (Hall y Wolf, 2019).

Pero ¿en qué consiste la desinformación? La desinformación puede presentarse de diversas maneras; Wardle (2020) establece siete categorías: contenidos engañosos; información sacada de contexto (por ejemplo, una imagen antigua de un evento anterior que vuelve a circular); contenido impostor, es decir, firmado falsamente por periodistas que no lo han escrito (o con logos de organizaciones que no los han creado); contenido manipulado o fabricado; desinformación en forma de sátiras o parodias y clickbait o "ciberanzuelos" que utilizan titulares sensacionalistas para lograr el mayor número de clicks posibles con vistas a generar ingresos de publicidad. 
Detrás de las fake news que circulan por las redes sociales existe una profunda confluencia de cuestiones incluyendo, en numerosas ocasiones, la politización coordinada, la desconfianza pública en las nuevas organizaciones, e incluso fallos de tecnología y de las plataformas de información para reconocer su papel y resolver la propagación de la desinformación (Zimdars y McLeod, 2020).

Este panorama empeora más aún ya que las noticias falsas en las redes sociales se propagan mucho más rápidamente que las verdaderas. Según la investigación de Vosoughi y colaboradores, en la que se analizan la difusión diferencial de las noticias de Twitter en el periodo 2006-2017, las noticias falsas se difundieron significativamente más rápido, más lejos y más ampliamente que las verdaderas en todas las categorías de la información y los efectos fueron especialmente pronunciados en el caso de noticias falsas sobre temas políticos; y al contrario de lo que podríamos pensar, los robots aceleraron la propagación de ambos tipos de noticias (verdaderas y falsas) al mismo ritmo, lo que implica que las noticias falsas se difunden más que las verdaderas porque los humanos somos más propensos a difundirlas (Vosoughi y otros, 2018).

Finalmente, entre los recientes trabajos relacionados con nuestra investigación sobre el tema podemos encontrar los siguientes: en LázaroRodríguez y Herrera-Viedma (2020) se analiza la producción de noticias sobre el coronavirus en los medios de comunicación españoles utilizando la base de datos MyNews; los resultados muestran que los medios digitales son los que más han publicado sobre el tema, con un claro aumento a partir de decretarse el estado de alarma en nuestro país.

Costa-Sánchez y López-García (2020) analizan la fórmula de comunicación adoptada en España durante la pandemia contrastándola con las recomendaciones de comunicación de crisis, y en cuanto a la cobertura periodística, señalan ejemplos de alarmismo y sensacionalismo en el tratamiento informativo de la misma.

En el trabajo de Pérez-Dasilva y otros (2020) se estudia y visualiza la red de noticias falsas que circulan en Twitter sobre el coronavirus utilizando la técnica del análisis de redes sociales; los resultados muestran que la situación de Estados Unidos predomina en la conversación (aunque Europa se había convertido en ese momento en el epicentro global de la pandemia), y entre los actores más destacados de la red se observa la escasa presencia de científicos e instituciones que ayuden a desmentir los bulos con información veraz y útil para contener el brote.
Casero-Ripollés (2020) analiza la influencia del coronavirus en el consumo de noticias en Estados Unidos y la capacidad de los ciudadanos para detectar noticias falsas sobre este tema; según este estudio, en situaciones críticas como ésta, el consumo de noticias se incrementa claramente (un $32 \%$ sobre el periodo previo a las crisis sanitaria), y los medios tradicionales, especialmente la televisión, son los que obtienen porcentajes más altos tanto en el consumo de noticias como en la valoración positiva en credibilidad por parte del público.

En Thelwall y Levitt (2020) se examinan informaciones vertidas en Twitter sobre el coronavirus relacionadas con la discapacidad para observar el impacto que tienen en personas particularmente vulnerables y los resultados confirman que Covid-19 se percibe como una gran amenaza para las personas con discapacidad en Twitter. Por otro lado, en Thelwall y Thelwall (2020) se estudia la reacción pública de las informaciones sobre el coronavirus difundidas en Twitter bajo la perspectiva de las diferencias de género. Los resultados muestran que las mujeres tienen más probabilidades de tuitear sobre el virus en el contexto de la familia, el distanciamiento social y la atención médica, mientras que los hombres tienen más probabilidades de tuitear sobre las cancelaciones deportivas, la propagación global del virus y las reacciones políticas.

Orduña-Malea y colaboradores llevan a cabo un análisis métrico de los videos sobre el coronavirus relacionados con España, difundidos en YouTube para determinar su volumen, su impacto y los canales a través de los cuales se han difundido. Los resultados muestran que la producción de videos sobre Covid-19 se incrementó a partir de la declaración del estado de alarma y los medios de comunicación, tanto nacionales como regionales, son el canal que aporta mayor cantidad de documentos audiovisuales sobre el tema. En cuanto al impacto, los vídeos relacionados con entretenimiento (categorías Gente y Blogs, y Entretenimiento) presentan un gran volumen de vídeos pero con menor impacto, mientras que los vídeos de las categorías de Educación y Ciencia y Tecnología son menos numerosos pero con un alto impacto, especialmente en visualizaciones (Orduña-Malea y otros, 2020).

En el trabajo llevado a cabo por Masip y otros (2020) se realiza una encuesta a nivel nacional a más de un millar de personas sobre su consumo informativo en el periodo de confinamiento y su percepción de la labor de los medios de comunicación en el tratamiento de la pandemia. Los resultados muestran que el consumo se ha incrementado en un $78 \%$ y la percepción de la mayoría de encuestados coincide en que los medios informan condicionados por su ideología y de forma sensacionalista 
generando una alarma social innecesaria. Ese sesgo ideológico es otro elemento que contribuye a la "infodemia" y a la pérdida de confianza en los medios.

En esta línea se encuentran también los trabajos de Igartua y otros (2020), y Moreno y otros (2020). En el primero, se realiza una encuesta a nivel internacional sobre los usos de la comunicación en el contexto del coronavirus en la que participan personas de veintiséis países; los resultados muestran que existen diferencias significativas en función de la edad y del país de residencia y el análisis realizado permite comprobar que la influencia del consumo de información redunda en la adopción de medidas de prevención. Moreno y otros (2020) se basan también en una encuesta en línea, a nivel nacional, realizada en España durante el mes siguiente a la declaración del estado de alarma sobre el comportamiento en la búsqueda de información y la confianza en las diferentes fuentes y canales. Tres de los cuatro canales de información más utilizados son los principales medios de comunicación; sin embargo, la segunda fuente de información más utilizada es WhatsApp, y la elección del medio influye en la percepción y aceptación de los mensajes sobre la crisis.

Por último, señalar el trabajo de Salaverría y otros (2020) en el que los autores realizan un análisis de contenido de los bulos relacionados con el coronavirus que circularon en España durante el primer mes del estado de alarma, a través de las tres plataformas de verificación acreditadas en nuestro país. El estudio muestra que los bulos sobre el coronavirus fueron difundidos principalmente por WhatsApp y también detectan los principales tipos de contenidos, aportando una tipología en la que se identifican distintos tipos de bulo.

\section{MATERIALES Y METODOLOGÍA}

En este trabajo vamos a utilizar la información que proporciona la herramienta Latam Chequea - Coronavirus (https://www.chequeado.com/latamcoronavirus/); se trata de una herramienta bastante completa de verificación de noticias sobre el Covid-19 con cobertura en España y Latinoamérica (en total, diecisiete países), fruto de un proyecto colaborativo coordinado por Chequeado (Argentina) en el que trabajan treinta y cinco organizaciones de verificación de datos de España y Latinoamérica (EFE Verifica, Maldita y Newtral, en el caso de España). Cuenta con el apoyo de Google News Initiative y su objetivo es ayudar a periodistas en la marea de desinformación creciente sobre el coronavirus (más información sobre el proyecto en https://latamjournalismreview.org/es/articles/ proyecto-colaborativo-de-fact-checking-en-ame- rica-latina-crea-plataforma-sobre-el-coronaviruspara-ayudar-a-periodistas/).

La herramienta recoge, entre otras informaciones, el país de origen del bulo, el título, descripción, organización que se encarga de la verificación, la calificación otorgada por los verificadores, tipo de información según su tema, fecha, formato, origen o canal empleado, fuente y, en su caso, los países por los que ha circulado, además del enlace a la desinformación, que ha resultado de gran utilidad a la hora de comprobar datos y despejar dudas.

Primero se procedió al volcado de los datos, en total 1.140 registros correspondientes a los supuestos bulos y noticias falsas difundidas durante el periodo transcurrido entre el $23 / 01 / 2020$ y el 03/05/2020 (aproximadamente quince semanas) que fueron analizadas por los equipos de chequeadores de verificación de noticias de las organizaciones que participan en el proyecto Latam ChequeaCoronavirus. Posteriormente, se normalizaron los datos para poder someterlos adecuadamente al tratamiento estadístico de los mismos utilizando la hoja de cálculo Excel, en el que se analizaron los siguientes datos:

- Producción de bulos en los distintos países.

- Producción de bulos normalizada por millón de habitantes.

- Evolución temporal del número diario de bulos a lo largo de las semanas de los países objeto de estudio en conjunto.

- Evolución temporal comparativa entre España y Latinoamérica del número diario de bulos a lo largo de las semanas.

- Calificaciones otorgadas por los chequeadores al conjunto total de noticias analizadas (Falso, Media verdad y Verdadero).

- Tipos de desinformación difundida en el conjunto de países según el tema (Medidas adoptadas, Situación de un país, Curas, etc.).

- Formatos de las desinformaciones (Texto, Video, Texto-Imagen, etc.).

- Principales canales utilizados para difundir las noticias (Redes sociales, Mensajería, etc.).

- Fuentes de las desinformaciones agrupadas en categorías según la profesión y/o actividad desempeñada (Medios, Miembros del gobierno, Profesionales de la salud, etc.).

- Redes de países por las que circulan los bulos, es decir, bulos originados en un país que se propagan a otros países. 
Una vez realizado este análisis, para profundizar en algunos aspectos, se recurrió al software estadístico SPSS para crear las tablas de contingencia con las variables principales objeto de estudio, con el fin de realizar un análisis cualitativo.

Para ver la relación entre variables cualitativas de las tablas de contingencia utilizamos el test ChiCuadrado de Pearson basado en la comparación de frecuencias observadas frente a frecuencias esperadas en dichas categorías. El resultado de dicho test indica si existen o no diferencias significativas entre dos variables cuantitativas en el conjunto de la tabla de contingencia. A continuación, para concretar qué es lo que contribuye a la asociación general que el estadístico Chi-Cuadrado $\left(X^{2}\right)$ mide, observamos los valores residuales individuales estandarizados. Esto resulta muy útil porque solo observando el valor residual podemos evaluar su significación: Si el valor se sitúa por encima de \pm 1,96 su significación es $p<0,05$, si el valor se sitúa por encima de $\pm 2,58$ su significación es $p<0,01$, y si se sitúa por encima de $\pm 3,29$ su significación es $p<0,001$. A menor valor de probabilidad $(p)$ la relación entre las variables, ya sea positiva o negativa, es más significativa (Field, 2009).

Las tablas de contingencia generadas y analizadas son las que relacionan las variables siguientes:

- Fuente y Calificación de la desinformación.

- País de origen y Calificación de la desinformación.

- Origen y Calificación de la desinformación.

- Tipo y Calificación de la desinformación.

- Formato de la desinformación y País de origen.

Por último, se ha utilizado la herramienta Google Trends para analizar en España las tendencias de búsquedas sobre el coronavirus en el periodo de estudio, observando las fechas de mayor afluencia, así como los principales temas y consultas relacionadas con dicha búsqueda.

Resumiendo, en el presente trabajo se han analizado cuantitativamente los siguientes datos, entre otros, y a nivel global: el volumen de desinformación por país (tanto en datos absolutos como normalizados), la línea de evolución temporal de los mismos, el tipo de desinformación según su temática, el origen o canal de la información, las fuentes (agrupándolas éstas en distintas categorías), y las redes de circulación de los bulos entre distintos países. Asimismo, a nivel local, se ha analizado para el caso de España, la correlación en la producción de los bulos con la evolución de la pandemia, y las tendencias de búsquedas en internet sobre el coronavirus.

\section{RESULTADOS}

Consultada la base de datos Latam Chequea Coronavirus a fecha del 4 de mayo, la aplicación arroja 1.140 resultados que consisten en desinformaciones recogidas principalmente en los medios de comunicación, redes sociales y mensajería (casi en su totalidad vía WhatsApp) en España y Latinoamérica durante el periodo transcurrido entre el $23 / 01 / 2020$ y el $03 / 05 / 2020$.

En cuanto a la producción de bulos, de los diecisiete países recogidos en la aplicación, el país con mayor número de bulos en el periodo de estudio es España, que duplica ampliamente a Colombia, Argentina y México, los tres países latinoamericanos con mayor número de desinformaciones (ver Fig. 1); en las últimas posiciones encontramos a Uruguay y República Dominicana, que no llegan a la docena. El promedio de bulos por país está en torno a 67. Hay que señalar que Brasil, México, Argentina, Colombia y Ecuador se encuentran a la cabeza, dentro de los países latinoamericanos, en mayor uso de la red social Twitter sobre el Covid-19 (Banda y otros, 2020).

Sin embargo, si normalizamos estos datos teniendo en cuenta la tasa de habitantes (Fig. 2), observamos algunos cambios importantes, siendo ahora Costa Rica el país con más desinformaciones por millón de habitantes con mucha diferencia, seguido de España y Ecuador; mientras, México y Brasil están ahora entre las últimas posiciones. En este caso, el promedio de bulos normalizado a la tasa de habitantes por país es 37,97.

En ambos casos hay que señalar que España se encuentra en las primeras posiciones. La línea de Pareto nos indica el porcentaje acumulado y, según podemos ver, con tan solo los tres primeros países llegamos al $50 \%$ de los casos y con los cinco primeros (Costa Rica, España, Ecuador, Bolivia y Nicaragua) obtenemos el $70 \%$ de los mismos.

Respecto a los países latinoamericanos que van a la cabeza, según un informe técnico especial sobre el Covid-19 de la Comisión Económica para América Latina y el Caribe (CEPAL, 2020), estos forman parte de los que cuentan con instalaciones sanitarias insuficientes, encontrándose por debajo significativamente del promedio del número de camas de hospital por cada 1.000 personas de América Latina.

En cuanto a la evolución de los bulos a lo largo del periodo analizado, la media de bulos diarios detectados en el periodo se sitúa en torno a $12(12,37)$ globalmente, es decir, considerando el conjunto de países. Si consideramos el caso de España, el promedio de desinformaciones diarias sería 4,36, frente al promedio de 9,16 en Latinoamérica. 
Figura 1. No total de desinformaciones por país de origen, en España y América Latina

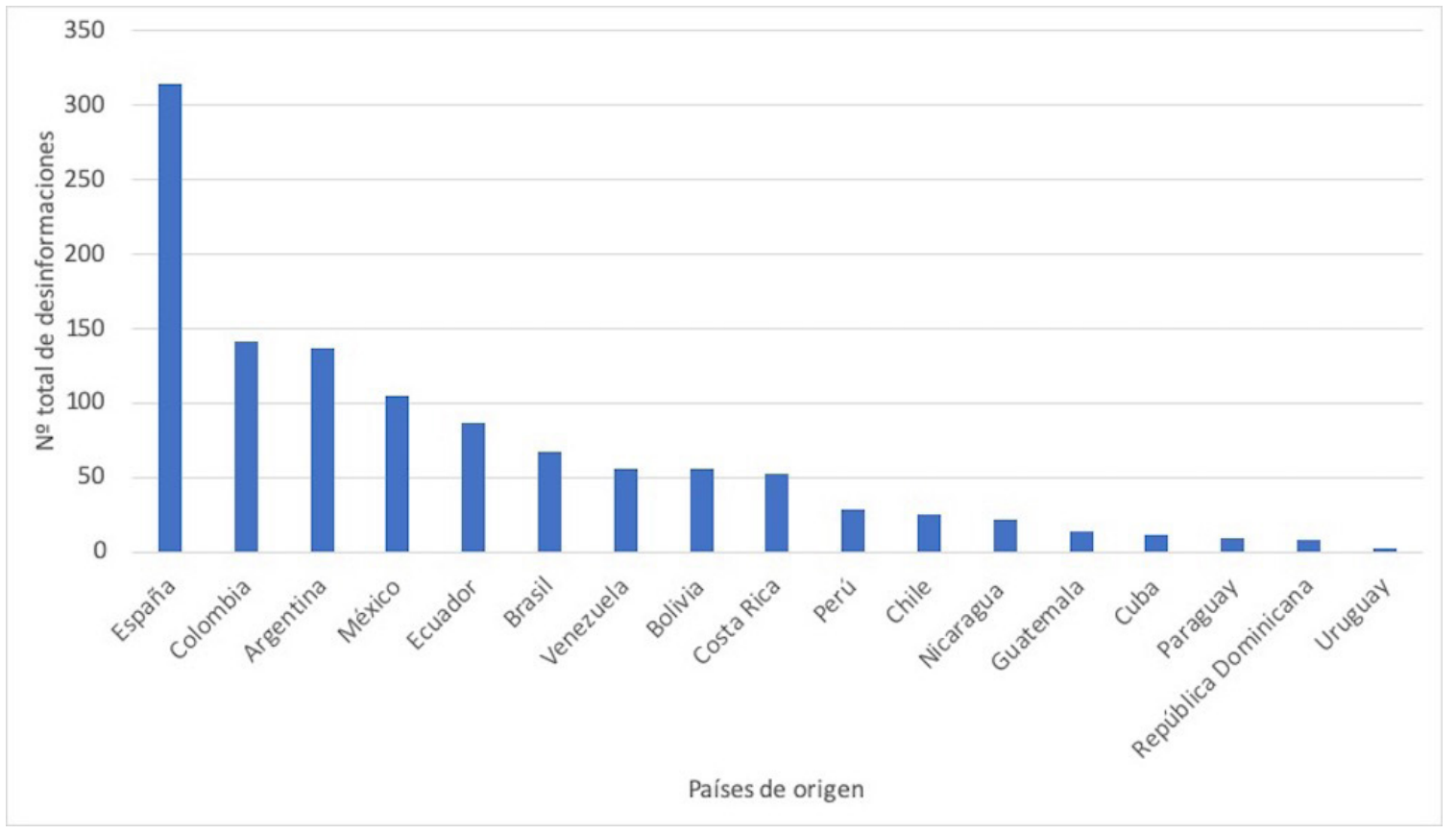

Figura 2. No de desinformaciones por millón de habitantes por país de origen, en España y América Latina

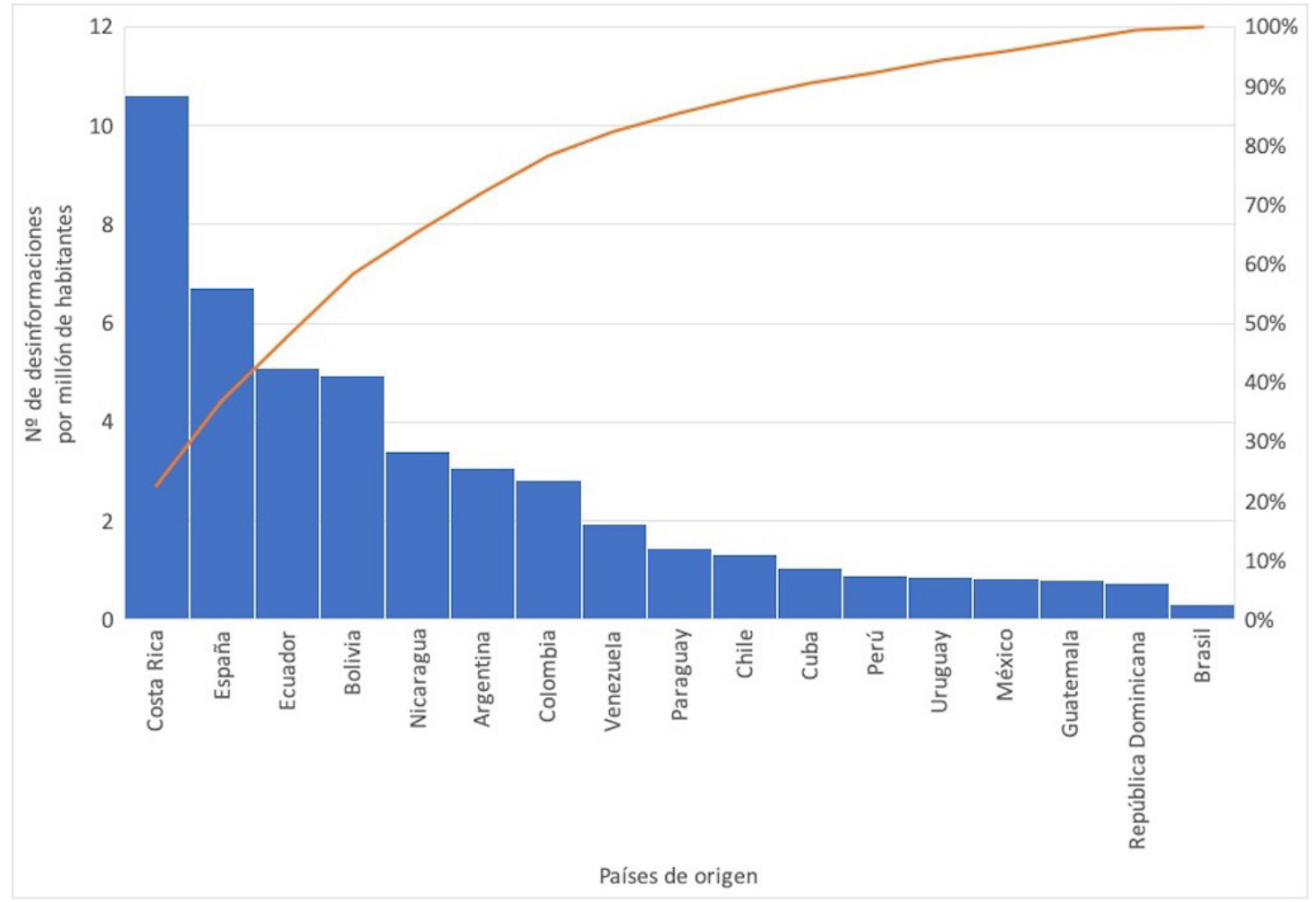

Además se puede observar (Fig. 3) que prácticamente, en cada semana, se produce al menos un pico, y que a partir de finales de febrero-primeros de marzo se empiezan a incrementar el numero de desinformaciones, presentando el primer pico importante el 12 de marzo, y alcanzando los valores más altos entre el 17 de marzo y el 8 de abril, valores que oscilan entre los 35-38 
bulos diarios en los picos más altos, y 9-10 en los más bajos, con un promedio de 25,52 ; es decir, duplicándose el promedio de bulos diarios. Hay que recordar que la OMS declaró la pandemia a nivel mundial por el Covid-19 el día 11 de marzo (OMS, 2020b).

Estos datos concuerdan con el conjunto de datos de las conversaciones sobre Covid-19 en la red social Twitter (Banda y otros, 2020), ya que tal como indican los autores, en las primeras semanas (desde el 1 de enero de 2020 hasta el 11 de marzo de 2020) el número de tweets es muy bajo y, sin embargo, se produce un aumento dramático paralelo a la propagación del virus, llegando a los 4 millones al día a partir del 11 de marzo. En Thelwall y Levitt (2020) también se produce este incremento a partir de la declaración de la pandemia.

Analizando de manera comparativa la evolución temporal entre España y Latinoamérica (Fig. 4) se observa un leve desplazamiento, ya que en España empiezan a incrementarse de manera continua los bulos a partir de la declaración del estado de alarma del 14 de marzo (Real Decreto 463/2020), y se alcanzan los valores más altos entre el 20 de marzo y el 11 de abril.

En España, este incremento producido en la desinformación a partir del estado de alarma concuerda con resultados similares en otros trabajos relacionados, en los que por ejemplo, aumenta considerablemente la producción de noticias sobre el Covid-19 en los medios digitales (LázaroRodríguez y Herrera-Viedma, 2020), así como la publicación de videos relacionados en YouTube (Orduña-Malea y otros, 2020); el consumo informativo también aumenta tras la declaración del mismo (Masip y otros, 2020). De manera similar, en Estados Unidos, la declaración del estado de emergencia provocó un gran aumento del consumo de información por parte de los ciudadanos (Casero-Ripollés, 2020).

Comparando esas fechas con las correspondientes a la tasa de crecimiento de la pandemia en España según los datos del Ministerio de Sanidad (https:// cnecovid.isciii.es/covid19/\# declaraci\%C3\%B3nagregada), podemos ver que coinciden con las fechas en las que la tasa de duplicación de casos se dispara situándose en 2,6 días, alcanzándose la fecha pico el 26 de marzo, y empezando a reducirse dicha tasa significativamente hacia mitad de abril (ver Fig. 5).

Como señalan Igartua y otros (2020), la divulgación diaria en los medios de comunicación del número de contagios y de fallecidos, más la alarma generada en las primeras etapas ante la necesidad de aplanar la curva, contribuyeron al incremento de percepción de la gravedad de la enfermedad, lo que ha influido en el incremento de desinformaciones sobre la misma.

Figura 3. Evolución temporal del número diario de bulos a lo largo de las semanas, en España y América Latina

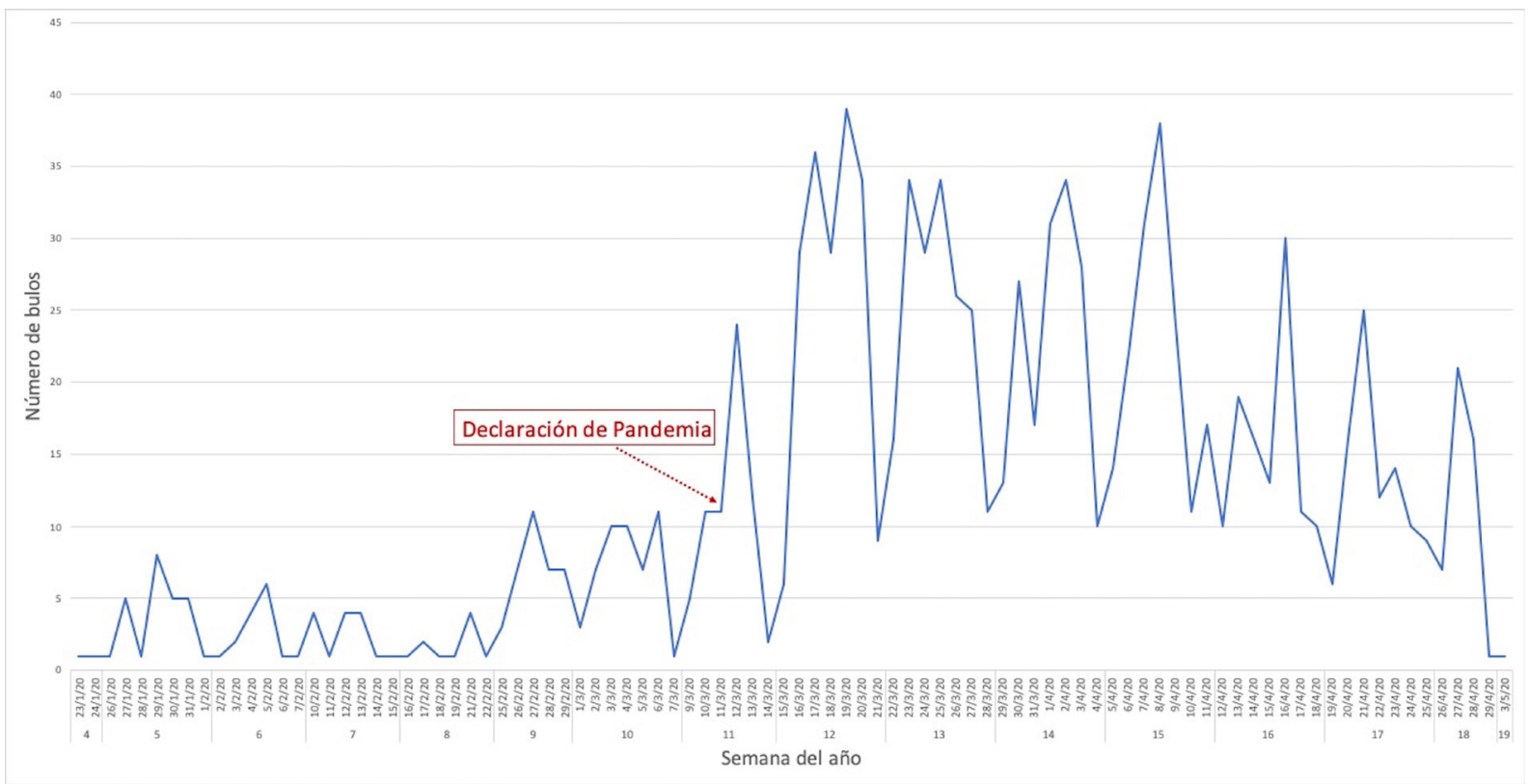


Figura 4. Evolución temporal comparativa entre España y Latinoamérica del número diario de bulos a lo largo de las semanas

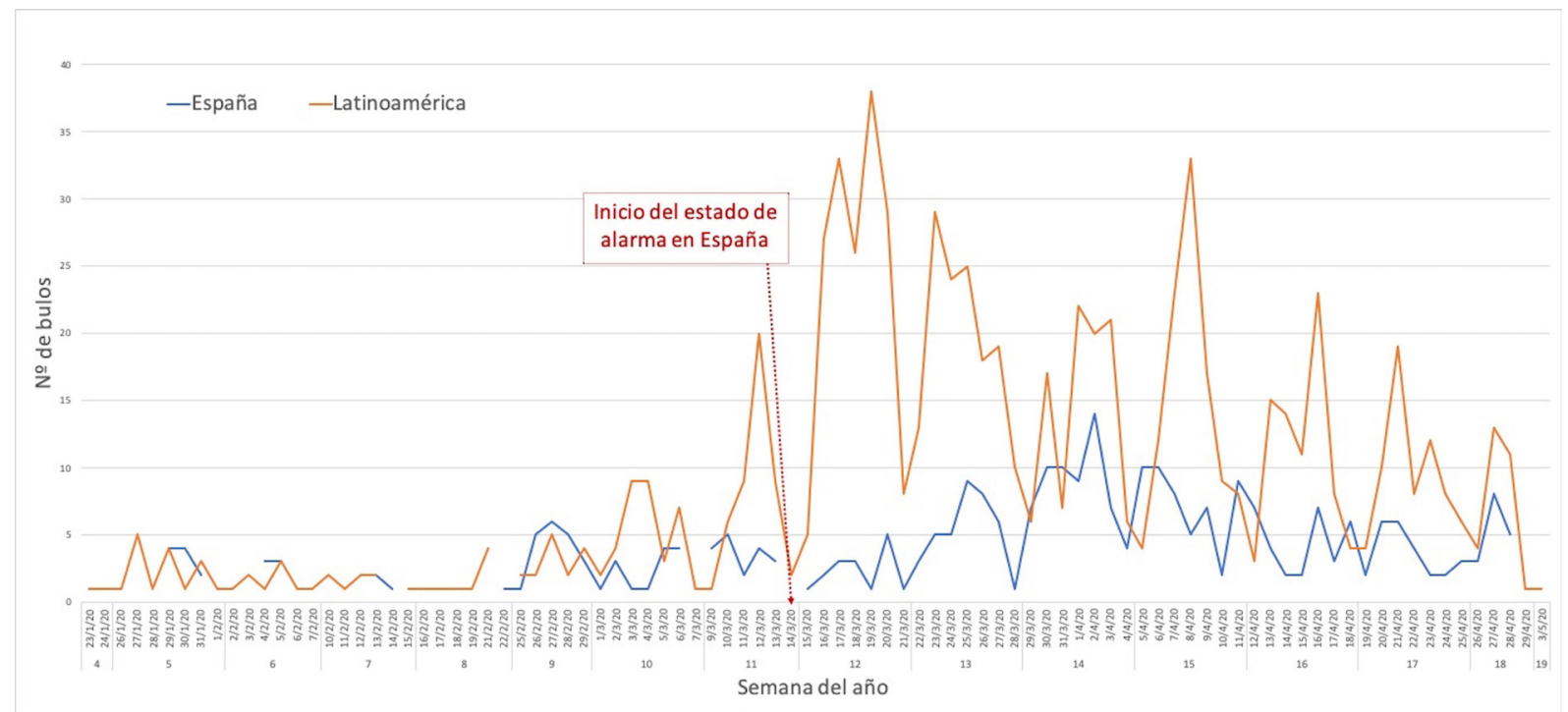

Figura 5. Curva de crecimiento de la pandemia en España

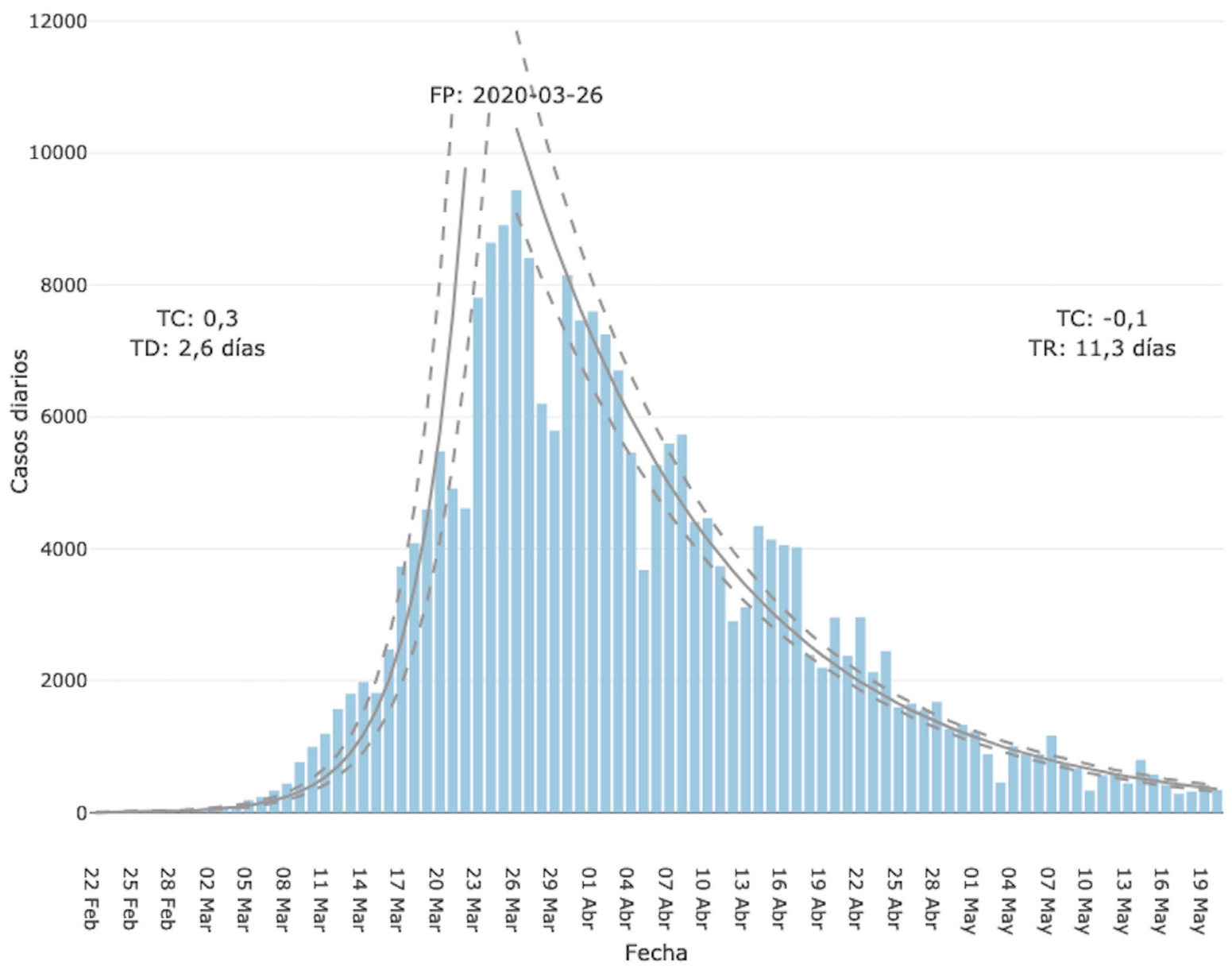

Fuente: Ministerio de Sanidad, Gobierno de España, https://cnecovid.isciii.es/covid19/ 
Dejando de lado estas pequeñas diferencias en la evolución de las noticias falsas entre España y Latinoamérica, y examinando las dos curvas correspondientes a ellas de la Fig. 4, se intuyen claramente patrones comunes en el comportamiento que se comprueban al calcular el coeficiente de correlación de Pearson de ambos conjuntos, obteniéndose 0,76 (siendo 1 el valor máximo), lo que indica una fuerte correlación entre ambos.

Por otro lado, y como cabía esperar, del total de noticias del conjunto de países evaluadas por los chequeadores, y según sus calificaciones otorgadas, tan solo el $2 \%$ son verdaderas. Mientras el $89 \%$ son falsas frente a un $9 \%$ que pueden considerarse como medias verdades; en este último grupo se han englobado calificaciones otorgadas por los chequeadores como media verdad, manipulado, fuera de contexto, parcialmente falso, engañoso, etc. Hay que señalar que tal como indican Salaverría y otros (2020), se trata de tipos de desinformaciones que en ocasiones no resultan fáciles de distinguir entre sí, pues muestran cierto solapamiento, y en nuestro caso ocurre especialmente en el último grupo de media verdad; por eso se ha procedido a agruparlos en una única clasificación.

Respecto a las calificadas como Verdadero, cabe señalar que la mitad de ellas tienen su origen en Colombia, y el resto está repartido, en orden decreciente, entre Argentina, México, Brasil, España, Guatemala y Perú. Y si analizamos la fuente, como podríamos esperar, el $74 \%$ proceden de fuentes fiables como miembros del gobierno, otros cargos públicos y medios de comunicación.
En cuanto al tipo de desinformación, según la temática, que se difunde en el conjunto de países (ver Fig. 6), destacan principalmente (además de la categoría Otros, que supone un $24 \%$ del total), Medidas adoptadas y Situación de un país igualadas ( $16 \%$ cada una), seguidas por las referidas a Curas $(14 \%)$ y Prevención (11\%).

Clasificando estos temas en dos grandes grupos, uno referido a los bulos sobre temas relacionados con el gobierno (Medidas adoptadas, Situación de un país y Declaraciones de autoridades) y otro grupo sobre temas sanitarios y científicos (Curas, Prevención, Contagios, Síntomas, Predicción, Origen del virus y Características del virus), el porcentaje de desinformaciones correspondiente al primer grupo sería en torno al $32 \%$, mientras que el correspondiente al segundo grupo estaría alrededor del $44 \%$ (con un $24 \%$ correspondientes a Otros, que estaría fuera de la clasificación anterior); resultados que concuerdan, en cierto modo, con los obtenidos en un trabajo similar (Salaverría y otros, 2020) pero circunscritos a España y en un periodo inferior (un mes).

En cuanto a los formatos de las desinformaciones, destaca ampliamente el texto, recogiendo casi la mitad de las noticias (el 46\%), probablemente por su facilidad e inmediatez para generar y difundir los bulos, seguido a mucha distancia por el vídeo (que supone el $16 \%$ de las noticias analizadas), la combinación de texto-imagen (en un $13 \%$, muy común por ejemplo en los bulos fuera de contexto), y la imagen (10\%). Sin embargo, el formato audio es de los menos utilizados, con tan solo un $6 \%$ de los casos.

Figura 6. Tipos de desinformación según temática

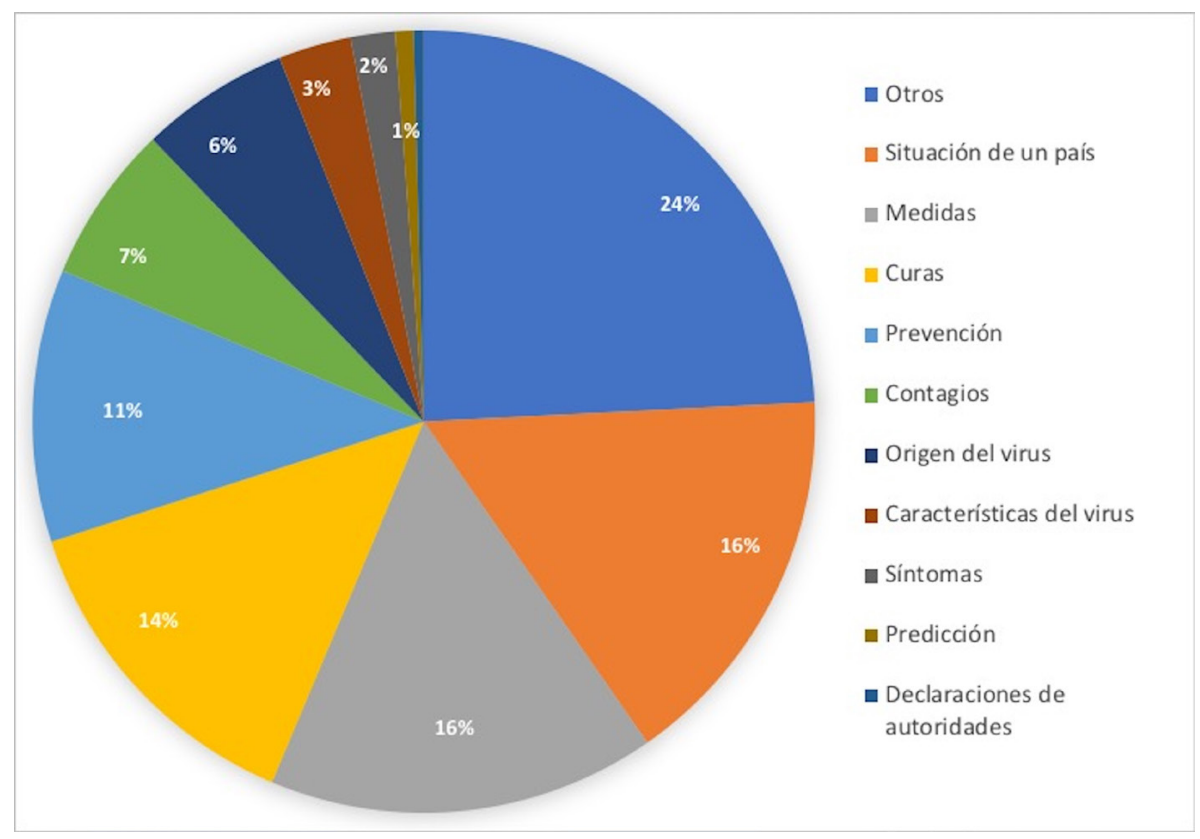


Respecto al origen de la información, los canales utilizados para la difusión son los siguientes (Fig. 7): en primer lugar, predominan las redes sociales con un $55 \%$ de los casos, englobando en ellas Facebook, la más utilizada en este contexto, seguida por Twitter, y en menor medida YouTube e Instagram, con apenas representación (tan solo un $1,75 \%$ del total). Estos resultados evidencian que las redes sociales más visuales como Instagram y YouTube no se han utilizado prácticamente para difundir noticias falsas, al igual que tampoco se han utilizado mucho para transmitir información sobre el coronavirus (Igartua y otros, 2020).

En segundo lugar, se encuentra con un 33\% del total, la mensajería (con un contundente predominio de WhatsApp) y, en tercer lugar, con un $8 \%$, los medios de comunicación, (principalmente, prensa, radio y televisión de ámbito nacional y regional). También nos encontramos con bulos que tienen su origen en varios canales simultáneamente, destacando especialmente el grupo de redes sociales y mensajería (principalmente Facebook y WhatsApp).

Llama la atención que, aunque en el conjunto de los diecisiete países analizados la red social predominante en bulos es Facebook, en el caso de España, la primera posición la ocupa Twitter, resultados que concuerdan con otros trabajos relacionados como el de Salaverría y otros (2020) y explican varias investigaciones que se centran únicamente en Twitter (Ghenai y Mejova, 2018; Pérez-Dasilva y otros, 2020; Thelwall y Thelwall, 2020; Thelwall y Levitt, 2020). Hay que señalar que Twitter es la red social predominante en temas relacionados con la salud $y$, por tanto, también en desinformaciones sobre la misma, como se puede observar en la revisión sistemática de la literatura sobre la difusión de desinformación relacionada con la salud en las redes sociales (Wang y otros, 2019).

Un aspecto importante que recoge la herramienta Latam Chequea - Coronavirus es la fuente. Hemos procedido a agrupar éstas en distintas categorías según la profesión y/o actividad desempeñada principalmente (ver Fig. 8). Como podíamos esperar, la inmensa mayoría de las desinformaciones es de fuente desconocida (el $72 \%$ de los mismas) y en el $28 \%$ restante correspondiente a una fuente conocida podemos observar, y esto es preocupante, los medios de comunicación como fuente predominante con un $8 \%$ de los casos (y si sumamos a estos los correspondientes a periodistas llegaríamos al $9 \%$ ), seguidos por personalidades con un papel importante en la pandemia como jefes y miembros de gobierno, así como otros cargos públicos (en conjunto alcanzarían el 5\%). Sin embargo, frente a lo que podríamos pensar, las fuentes procedentes de usuarios anónimos solo representan el 3\% de los casos. Respecto a los medios de comunicación, en un análisis estadístico posterior llevado a cabo generando tablas de contingencia se observa, afortunadamente, que las desinformaciones recogidas en los medios suelen ser verdaderas.

Figura 7. Principales canales utilizados para difundir las noticias

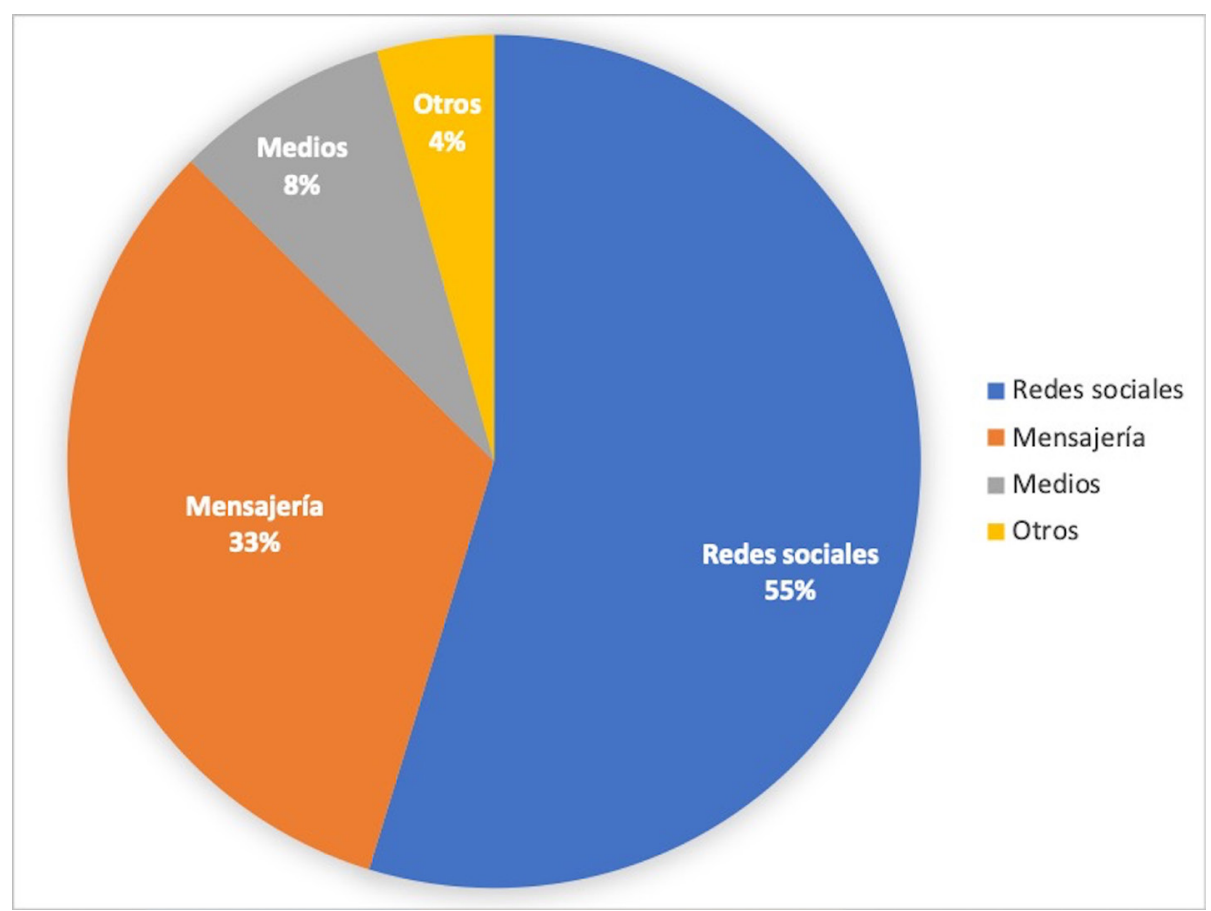


Figura 8. Fuentes de las desinformaciones agrupadas en categorías

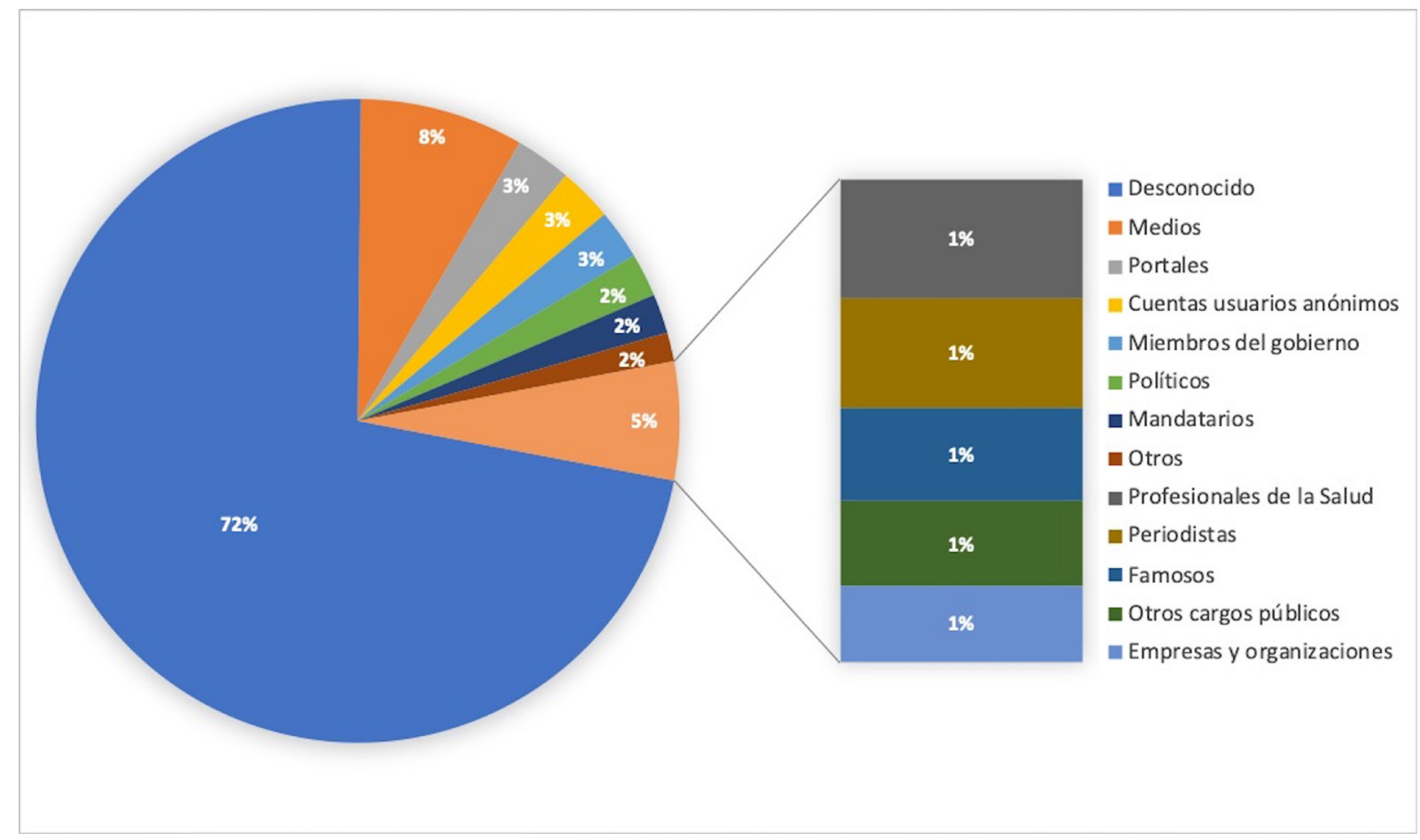

Otro aspecto interesante que también permite analizar esta herramienta son las redes de países que se forman por las que circulan los bulos; es decir, un bulo originado en un país en numerosas ocasiones traspasa fronteras y se extiende por otros países, información que también está disponible en la plataforma. Analizando estos datos tenemos un promedio de 2,53 países por los que circulan los bulos (sin contar el país de origen). En este aspecto destacan Paraguay (con un promedio de 5,5 países), Guatemala y Costa Rica (4 y 3,44, respectivamente), mientras que en España, el promedio de países por los que se extiende un bulo está en torno a 2 .

En la Fig. 9 se pueden observar estas redes de circulación de las desinformaciones. Como se puede ver, en España los bulos se propagan principalmente a Estados Unidos, México y Colombia; y, en menor medida, a Francia, Ecuador y Venezuela, aunque también han llegado en algunas ocasiones a destinos como Canadá, China, Australia e India, consecuencia directa de la globalización que hace del mundo un lugar cada vez más interconectado.

Y de los países con más promedio en circulación externa anteriormente citados, en el caso de Guatemala, los bulos sólo se expanden a otros países latinoamericanos, mientras que Paraguay y Costa Rica lo hacen además a otros continentes como Eu- ropa (en concreto a España y Francia), Australia, además de Canadá y Estados Unidos.

Con el fin de ahondar en algunos aspectos de este análisis, se han generado distintas tablas de contingencia en SPSS con las principales variables de estudio, y una de las más interesantes es la generada entre la Fuente y la Calificación de la desinformación (Tabla I). Como se aprecia, existe una relación estadísticamente significativa entre las fuentes y la calificación, con un Chi-Cuadrado $X^{2}$ de 74,099 y una probabilidad $p<0,001$, por lo tanto se rechaza la hipótesis nula de no existencia de relación estadística significativa entre las variables.

En esta tabla se encuentran marcadas en rojo aquellas fuentes que presentan una relación significativa con alguna de las calificaciones, siendo esta relación mayor conforme aumentan los valores de los residuales, tal como se explica en el apartado de metodología. En la tabla se indican tanto el número de casos (count) como los valores residuales (Std. Residual) obtenidos en cada fuente para cada una de las tres calificaciones de la desinformación (Falso, Verdadero, Media verdad).

Como se puede observar en la Tabla I, el total de casos analizados en la tabla de contingencia (871) es menor que el total de noticias (1.140) recogidas en la plataforma Latam Chequea-Coronavirus de- 
Figura 9. Redes de países por las que circulan los bulos

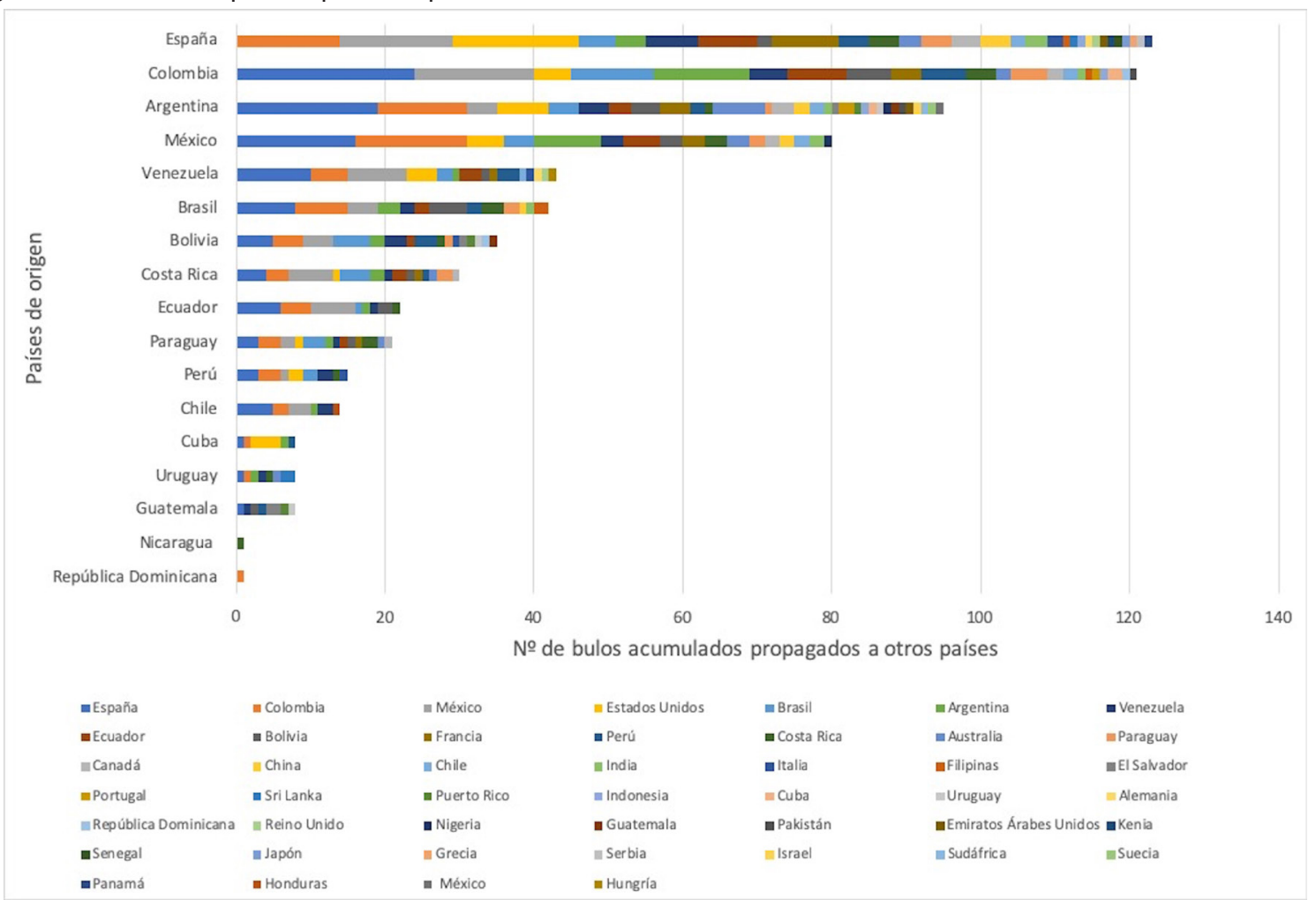

bido a que para el análisis se excluyeron, en este caso, las fuentes con menos de 7 desinformaciones, porque al no aportar un número representativo se generaba en la tabla de contingencia muchas cuadrículas con valores nulos o muy bajos, lo cual incrementaba en exceso el tamaño de la tabla sin aportar información relevante. Hay que señalar, además, que en algunos casos los verificadores no rellenan en la plataforma todos los campos de algunas desinformaciones.

El análisis $X^{2}$ de la Tabla I permite abordar las diferencias de calificación entre las distintas fuentes de información. Se muestra una significativa asociación entre las variables Fuente de la desinformación y Calificación de la desinformación, con un $X^{2}=79,09$ y $p<0,001$. Basándose en los residuales esto parece representar, por un lado, el hecho que los valores de las fuentes Miembros el gobierno, Políticos y Otros cargos públicos catalogados como Media verdad fueron claramente superiores al resto de las fuentes. Por otro lado, los valores residuales de las fuentes Medios, Portales, Miembros del Gobierno, Otros cargos públicos y Empresas y organizaciones catalogados como Verdadero son sensiblemente superiores al conjunto del resto de las fuentes. Por el contrario, los valores de la fuente Desconocido catalogados como Verdadero son claramente inferiores al resto de las fuentes.
Tomando como ejemplo los valores significativos de la fuente Medios catalogados como Verdadero, se observan unos residuales:

$$
\frac{5}{68-5}=\frac{5}{63}=0,0793
$$

Para el resto de las desinformaciones ajenas a Medios y catalogadas como Verdadero los residuales serían:

$$
\frac{10}{871-68-10}=\frac{10}{793}=0,0126
$$

El cociente de residuales se calcularía dividiendo los residuales de Medios catalogados Verdadero entre los residuales del resto de las fuentes no catalogadas como Verdadero:

$$
\frac{0,0793}{0,0126}=6,29
$$

Lo que significa que los residuales de las desinformaciones calificadas como Verdadero fueron 6,29 veces superiores cuando pertenecían a los Medios que cuando pertenecían al resto de las fuentes. Puede comprobarse que en el conjunto de desinformaciones catalogadas en la tabla dinámica como Verdadero (15), la contribución de los medios representa el $33,3 \%$, muy superior al resto de las fuentes. 
Tabla I. Tabla de contingencia entre la Fuente y la Calificación de la desinformación

\begin{tabular}{|c|c|c|c|c|}
\hline \multicolumn{5}{|c|}{ Fuente de la desinformación * Calificación de la desinformación Crosstabulation } \\
\hline & & \multicolumn{3}{|c|}{ Calificación de la desinformación } \\
\hline & & FALSO & VERDADERO & $\begin{array}{c}\text { MEDIA } \\
\text { VERDAD }\end{array}$ \\
\hline \multirow{2}{*}{ Desconocido } & Count & 597 & 4 & 41 \\
\hline & Std. Residual & 9 & $-2,1 *$ & $-1,9$ \\
\hline \multirow{2}{*}{ Medios } & Count & 53 & 5 & 10 \\
\hline & Std. Residual & $-1,0$ & $3,5 * * *$ & 1,7 \\
\hline \multirow{2}{*}{ Portales } & Count & 22 & 2 & 1 \\
\hline & Std. Residual &,- 1 & $2,4^{*}$ &,- 8 \\
\hline \multirow{2}{*}{ Cuentas usuarios anónimos } & Count & 22 & 0 & 3 \\
\hline & Std. Residual &,- 1 &,- 7 & 6 \\
\hline \multirow{2}{*}{ Miembros del gobierno } & Count & 16 & 2 & 5 \\
\hline & Std. Residual & $-1,0$ & $2,5^{*}$ & $2,1 *$ \\
\hline \multirow{2}{*}{ Políticos } & Count & 13 & 0 & 4 \\
\hline & Std. Residual &,- 6 &,- 5 & $2,1 *$ \\
\hline \multirow{2}{*}{ Mandatarios } & Count & 11 & 0 & 2 \\
\hline & Std. Residual &,- 2 &,- 5 & 8 \\
\hline \multirow{2}{*}{ Otros } & Count & 12 & 0 & 0 \\
\hline & Std. Residual & ,4 &,- 5 & $-1,0$ \\
\hline \multirow{2}{*}{ Profesionales de la Salud } & Count & 6 & 0 & 2 \\
\hline & Std. Residual &,- 4 &,- 4 & 1,6 \\
\hline \multirow{2}{*}{ Periodistas } & Count & 8 & 0 & 2 \\
\hline & Std. Residual &,- 3 &,- 4 & 1,2 \\
\hline \multirow{2}{*}{ Famosos } & Count & 10 & 0 & 1 \\
\hline & Std. Residual & 0 &,- 4 & 1 \\
\hline \multirow{2}{*}{ Otros cargos públicos } & Count & 6 & 1 & 3 \\
\hline & Std. Residual & $-1,0$ & $2,0 *$ & $2,3^{*}$ \\
\hline \multirow{2}{*}{ Empresas y organizaciones } & Count & 5 & 1 & 1 \\
\hline & Std. Residual &,- 5 & $2,5^{*}$ & ,5 \\
\hline
\end{tabular}

$* p<0,05 ; * * p<0,01 ; * * * p<0,001$

\begin{tabular}{|l|c|c|c|}
\hline \multicolumn{4}{|c|}{ Chi-Square Tests } \\
\hline & Value & df & Asymp. Sig. (2-sided) \\
\hline Pearson Chi-Square & $74,099^{\mathrm{a}}$ & 24 &, 000 \\
\hline Likelihood Ratio & 54,516 & 24 &, 000 \\
\hline Linear-by-Linear Association & $16,584^{\mathrm{c}}$ & 1 &, 000 \\
\hline N of Valid Cases & 871 & & \\
\hline
\end{tabular}

a. 23 cells $(59,0 \%)$ have expected count less than 5 . The minimum expected count is, 12 .

b. Cannot be computed because there is insufficient memory.

c. The standardized statistic is 4,072 . 
La evaluación puede llevarse a cabo entre distintas fuentes de desinformación. Si se compara la fuente Miembros del gobierno con la fuente Otros cargos públicos, los residuales de las desinformaciones calificadas como Media verdad serían 1,54 veces superiores cuando las realizan Otros cargos públicos que cuando la realizan los Miembros del gobierno, lo cual podría interpretarse que los cargos públicos no directamente relacionados con el gobierno son más proclives a decir medias verdades.

Según la información mostrada en la Tabla I, y a partir de los valores residuales, podemos señalar los siguientes resultados de este análisis:

- Las fuentes de origen Desconocido tienen una menor incidencia de desinformaciones calificadas como Verdadero frente al resto de las fuentes $(p<0,05)$.

- Los Medios ( $p<0,001)$, los Portales $(p<0,05)$, los Miembros del gobierno ( $p<0,05)$, Otros cargos públicos $(\mathrm{p}<0,05)$ y Empresas y Organizaciones $(p<0,05)$, por el contrario, tienen una elevada incidencia de calificaciones Verdadero frente al resto de las fuentes. De todas estas fuentes, destaca el peso que tienen los Medios sobre el resto, aglutinando el 33,33\% del total de noticias calificadas como Verdadero.

- Los Miembros del gobierno, los Políticos y Otros cargos públicos son, sin embargo, las únicas fuentes que tienen una significativa incidencia con la calificación Media verdad $(p<0,05)$. De entre las fuentes conocidas, estas fuentes son las que tienen más peso, ya que agrupan el 35,29\% de las desinformaciones calificadas como Media verdad.

Otros resultados interesantes obtenidos del análisis de las tablas de contingencia generadas en este trabajo son (pueden consultarse el resto de las tablas de contingencia en Anexos):

- Respecto a las relaciones significativas entre las variables País de origen y Calificación de la desinformación (Anexo I): España presenta una marcada incidencia negativa de las desinformaciones calificadas como Media verdad $(p<0,001)$; por el contrario, Colombia presenta una incidencia muy significativa con la calificación Verdadero $(p<0,001)$, y otra un poco menor con Media verdad $(p<0,01)$; por último, México y Bolivia presentan una alta incidencia $(p<0,001$ y $p<0,01$, respectivamente) con la calificación Media verdad. En general, agrupando los países latinoamericanos y contrastándolos con España (Anexo II), se observa que Latinoamérica, en su conjunto, tiene una mayor incidencia positiva con esta calificación, por lo que puede afirmarse que en estos países se producen más bulos del tipo de manipulación, y sacados de contexto, que en el nuestro.

- En cuanto al canal u origen de difusión, el Anexo III contiene las relaciones entre las variables Origen de la desinformación y Calificación de la desinformación, pudiendo observarse que las Redes sociales tienen una negativa incidencia $(p<0,05)$ con la calificación Verdadero. Sin embargo, la Mensajería (representada prácticamente en su totalidad por WhatsApp) presenta la misma negativa incidencia con la calificación Media verdad $(p<0,05)$. De lo descrito en los dos casos anteriores puede deducirse el impacto que supone el uso de estos canales tan populares e inmediatos en la difusión de noticias de actualidad. Por su parte, los $\mathrm{Me}$ dios confirmarían lo descrito anteriormente correspondiente a las fuentes, presentando una elevada incidencia positiva con Verdadero $(p<0,001)$, con un $43,8 \%$ de esta calificación. Finalmente, Otros presenta también una alta incidencia tanto con Verdadero como con Media verdad ( $p<0,001)$.

- Respecto al tipo o temática de la información, como puede observarse en el Anexo IV donde se muestran las relaciones entre las variables Tipo de desinformación y Calificación de la desinformación, el tipo Situación de un país muestra una incidencia significativa con la calificación Verdadero y con Media verdad $(p<0,05)$, y el tipo Características del virus una elevada con Media verdad $(p<0,001)$.

- Por último, en cuanto a las variables formato de la desinformación y País de origen (Anexo V), se observan incidencias significativas $(p<0,05)$ de México con Video, Venezuela con Texto y Bolivia con Texto-Imagen. Ecuador presenta una marcada incidencia con Texto-Imagen $(\mathrm{p}<0,01)$ y Perú con $A u$ dio $(p<0,001)$, que como comentamos anteriormente, es uno de los formatos menos utilizados. Destaquemos aquí el hecho de la importancia de los medios visuales y no escritos (o mezcla de texto con imágenes) en la difusión de la desinformación en los países con importantes poblaciones de bajo nivel educativo.

Finalmente, no cabe duda que esta "infodemia" de bulos sobre el coronavirus ha generado en la sociedad inquietud e incertidumbre, lo que ha disparado las búsquedas en internet relaciona- 
das con la pandemia a nivel mundial de un $50 \%$ a un $70 \%$ en todas las generaciones (OPS, 2020), al igual que en España, como se puede observar en la herramienta de tendencias de búsqueda Google Trends, que actualmente tiene un apartado de noticias destacadas sobre el coronavirus (https:// trends.google.es/trends/story/US_cu_fPCT5XABAAAfkM_en), desde la cual nos hemos descargado los datos que se muestran en la Fig. 10.

En dicha figura se puede observar como en España, en la segunda semana del mes de marzo, se disparan las búsquedas sobre el coronavirus, llegando al punto máximo 100 de popularidad (en la escala de 0 a 100) el 12 de marzo, habiendo declarado la OMS la pandemia el día anterior, descendiendo luego poco a poco, pasando del 75 al 50 de popularidad, con algunos picos, en la segunda quincena de marzo, y a partir del 19 de abril la popularidad de esta búsqueda desciende por debajo de 25.

Asimismo, los usuarios que han realizado esa búsqueda también han hecho otras consultas de búsqueda relacionadas: según Google Trends, los principales temas y consultas relacionados con dicha búsqueda en ese periodo, y que presentan mayor aumento de frecuencia de búsqueda son la curva de la pandemia, las cifras y fallecidos, un portal de estadísticas a tiempo real a nivel mundial (Worldometer) y rebrotes.

\section{CONCLUSIONES}

Una vez realizado el estudio se observa que, efectivamente, la evolución de la pandemia influ- ye en la propagación de los bulos, disparándose estos en momentos críticos como la declaración de pandemia por parte de la OMS (duplicándose el promedio de bulos diarios) y, en el caso concreto de España, en los momentos de mayor tasa de crecimiento de la curva, al mismo tiempo que las búsquedas sobre el tema en internet alcanzan su máxima popularidad.

Respecto a los diecisiete países analizados, España es de los países con mayor volumen de desinformación (tanto en valor absoluto como por tasa de habitantes), y en Latinoamérica, cumpliendo ambos indicadores, se sitúan a la cabeza Argentina y Ecuador. Por otro lado, la evolución temporal de las desinformaciones sigue el mismo patrón en España y Latinoamérica, como muestra la fuerte correlación entre ambos conjuntos de datos.

En cuanto al tipo de desinformación que se difunde, destacan principalmente Medidas adoptadas y Situación de un país seguidas por las referidas a Curas y Prevención.

Hay que señalar, como se podría esperar, que tan solo el $2 \%$ de las supuestas desinformaciones analizadas son calificadas por los verificadores como verdaderas, mientras que el $89 \%$ son falsas y un $9 \%$ pueden considerarse como medias verdades.

Respecto al canal de difusión destacan las redes sociales seguidas de WhatsApp, populares canales de comunicación que tienen un impacto inmediato sobre la difusión de noticias de actualidad. La gran mayoría de las noticias analizadas son de fuente Desconocido, pero dentro de las fuentes conocidas los medios de comunicación son la fuente predo-

Figura 10. Interés de búsqueda en España sobre el coronavirus realizadas en Google durante el periodo objeto de estudio

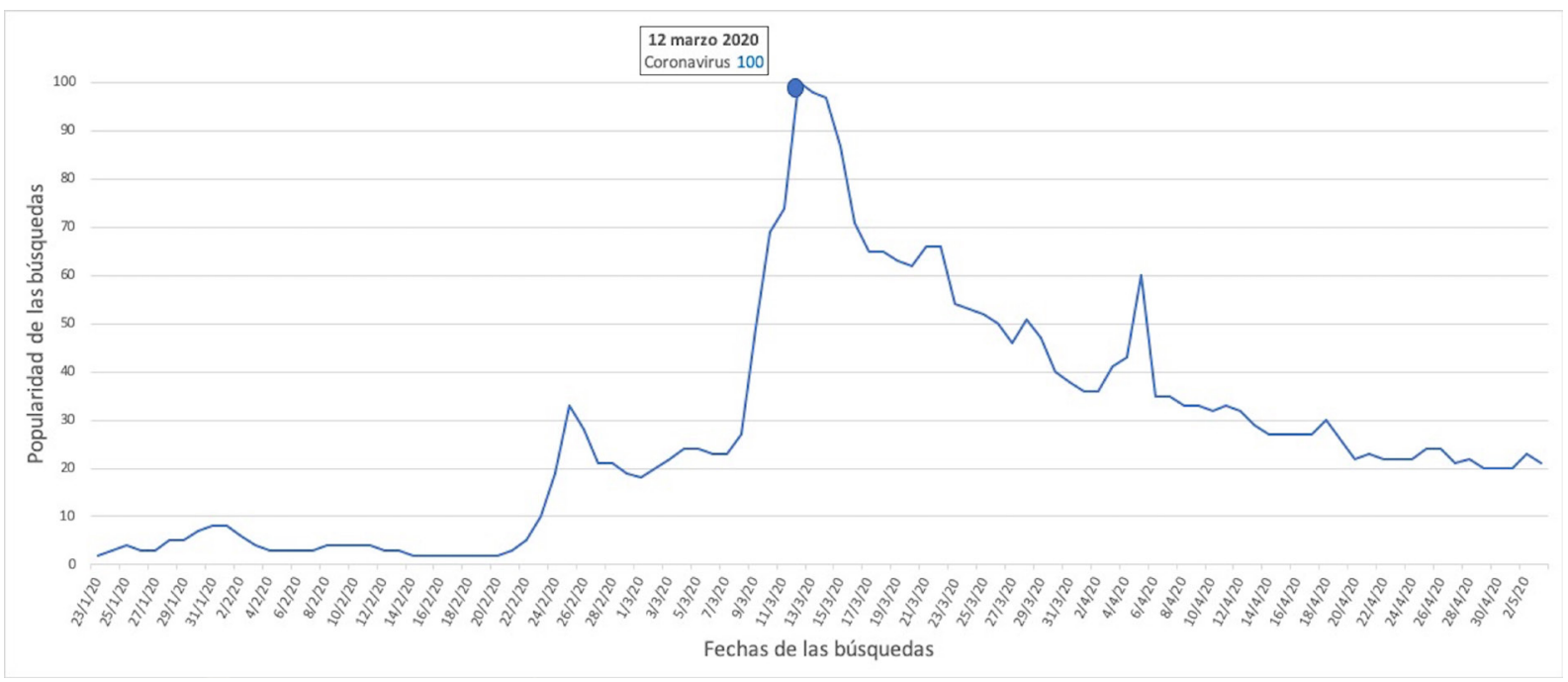


minante. Esto podría resultar preocupante visto su porcentaje de desinformaciones calificadas Falso sobre el total, pero es por el contrario, la fuente que tiene más peso dentro de las calificadas como Verdadero. En cambio, las fuentes que corresponden a cargos públicos y políticos tienen un peso destacado dentro de las desinformaciones catalogadas como Media verdad, es decir, información manipulada, fuera de contexto, parcialmente falsa,

\section{REFERENCIAS}

Adhanom, T.; Ng, A. (2020). Desinformación frente a medicina: hagamos frente a la 'infodemia'. Elpais.com, 18 de febrero de 2020. Disponible en: $\quad$ https://elpais.com/sociedad/2020/02/18/ actualidad/1582053544_191857.htm

Banda, J. M.; Tekumalla, R.; Wang, G.; Yu, J.; Liu, T.; Ding, Y.; Chowell, G. (2020). A Twitter Dataset of 150+ million tweets related to COVID-19 for open research (Version 4.0). Zenodo. http://doi.org/10.5281/ zenodo. 3738018

Casero-Ripollés, A. (2020). Impact of Covid-19 on the media system. Communicative and democratic consequences of news consumption during the outbreak. El profesional de la información, 29 (2), e290223. https://doi.org/10.3145/epi.2020.mar.23

CEPAL (Comisión Económica para América Latina y el Caribe) (2020). América Latina y el Caribe ante la pandemia del Covid-19. Efectos económicos y sociales. Informes técnicos, Naciones Unidas, 3 de abril de 2020. Disponible en: https://repositorio. cepal.org/bitstream/handle/11362/45337/S2000264_ es. pdf ?sequence $=6 \&$ isAllowed $=y$

Costa-Sánchez, C. ; López-García, X. (2020). Comunicación y crisis del coronavirus en España. Prime-ras lecciones. El profesional de la información, 29 (3), e290304. https://doi.org/10.3145/epi.2020.may.04

Depoux, A.; Martin, S.; Karafillakis, E.; Preet, R.; WilderSmith, A.; Larson, H. (2020). The pandemic of social media panic travels faster than the COVID-19 outbreak. Journal of Travel Medicine, 27(3), taaa031, https://doi.org/10.1093/jtm/taaa031

Erku, D. A.; Belachew, S. A. ; Abrha, S.; Sinnollareddy, M. ; Thomas, J.; Steadman, K. J.; Tesfaye, W. H. (2020). When fear and misinformation go viral: Pharmacists' role in deterring medication misinformation during the 'infodemic' surrounding COVID-19. Research in Social and Administrative Pharmacy, article in press. https:// doi.org/10.1016/j.sapharm.2020.04.032

Field, A. (2009). Discovering Statistics using SPSS. London: SAGE Publications Ltd.

Ghenai, A.; Mejova, Y. (2018). "Fake cures: User-centric modeling of health misinformation in social media". En: Karahalios, K.; Monroy-Hernández, A.; Lampinen, A.; Fitzpatrick, G. (eds.). Proceedings of the ACM on humancomputer interaction, 2 (CSCW), article 58, pp. 1-20. o engañosa. En este sentido, en Latinoamérica se producen más bulos de este tipo que en España.

Al hilo del tema de este artículo podemos concluir finalmente que es fundamental que sigan desarrollándose herramientas y plataformas de chequeo y verificación de noticias con el fin de luchar contra la "infodemia", que se muestra como la nueva pandemia informativa de este siglo.

New York, United States: Association for Computing Machinery. https://doi.org/10.1145/3274327

Hall, K.; Wolf, M. (2019). Whose crisis? Pandemic flu, 'communication disasters'and thestruggleforhegemony. Health. https://doi.org/10.1177/1363459319886112

Igartua, J. J.; Ortega-Mohedano, F.; Arcila-Calderón, C. (2020). Communication use in the times of the coronavirus. A cross-cultural study. El profesional de la información, 29 (3), e290318. https://doi. org/10.3145/epi.2020.may.18

Lázaro-Rodríguez, P.; Herrera-Viedma, E. (2020). Noticias sobre Covid-19 y 2019-nCoV en medios de comunicación de España: el papel de los medios digitales en tiempos de confinamiento. El profesional de la información, 29 (3), e290302. https://doi.org/10.3145/epi.2020.may.02

Masip, P.; Aran-Ramspott, S.; Ruiz-Caballero, C.; Suau, J.; Almenar, E.; Puertas-Graell, D. (2020). Consumo informativo y cobertura mediática durante el confinamiento por el Covid-19: sobreinformación, sesgo ideológico y sensacionalismo. El profesional de la información, 29 (3), e290312. https://doi. org/10.3145/epi.2020.may.12

Moreno, A.; Fuentes-Lara, C.; Navarro, C. (2020). Covid-19 communication management in Spain: Exploring the effect of information-seeking behavior and message reception in public's evaluation. El profesional de la información, 29 (4), e290402. https://doi.org/10.3145/epi.2020.jul.02

OMS (Organización Mundial de la Salud) (2020a). 2019$\mathrm{nCoV}$ outbreak is an emergency of international concern. Disponible en: http://www.euro.who.int/ en/health-topics/health-emergencies/coronaviruscovid-19/news/news/2020/01/2019-ncov-outbreakis-an-emergency-of-international-concern

OMS (Organización Mundial de la Salud) (2020b). Discurso de apertura del Director General de la OMS en la rueda de prensa sobre Covid-19 celebrada el 11 de marzo de 2020. Disponible en: https://www.who.int/dg/speeches/ detail/who-director-general-s-opening-remarks-at-themedia-briefing-on-covid-19---11-march-2020

ONU (Organización Naciones Unidas) (2020). La ONU lanza una iniciativa mundial contra la desinformación relacionada con el coronavirus. Noticias ONU, 21 de mayo de 2020. Disponible en: https://news.un.org/es/ story/2020/05/1474802 
OPS (Organización Panamericana de la Salud) (2020). Entender la infodemia y la desinformación en la lucha contra la Covid-19. Informes técnicos, 1 de mayo de 2020. Disponible en: https://www.paho.org/es/ documentos/entender-infodemia-desinformacionlucha-contra-covid-19

Orduña-Malea, E.; Font-Julián, C. I.; Ontalba-Ruipérez, J. A. (2020). Covid-19: análisis métrico de vídeos y canales de comunicación en YouTube. El profesional de la información, 29 (4), e290401. https://doi. org/10.3145/epi.2020.jul.01

Pérez-Dasilva, J. A.; Meso-Ayerdi, K.; MendigurenGaldospín, T. (2020). Fake news y coronavirus: detección de los principales actores y tendencias a través del análisis de las conversaciones en Twitter. El profesional de la información, 29 (3), e290308. https://doi.org/10.3145/epi.2020.may.08

Real decreto 463/2020, de 14 de marzo, por el que se declara el estado de alarma para la gestión de la situación de crisis sanitaria ocasionada por el Covid-19. BOE, n. 67, 14 marzo, pp. 25390-25400. https://www. boe.es/diario_boe/txt.php?id=BOE-A-2020-3692

Salaverría, R.; Buslón, N.; López-Pan, F.; León, B.; López-Goñi, I.; Erviti, M. C. (2020). Desinformación en tiempos de pandemia: tipología de los bulos sobre la Covid-19. El profesional de la información, 29 (3), e290315. https://doi.org/10.3145/epi.2020.may.15

Shimizu, K. (2020). 2019-nCoV, fake news, and racism. The Lancet, 395(10225), 685-686. https://doi. org/10.1016/S0140-6736(20)30357-3

Simon, F. (2020). Ethical questions related to Covid-19 and ENT practice. European Annals of Otorhinolaryngology,
Head and Neck Diseases, 137 (3), 155-156. https:// doi.org/10.1016/j.anorl.2020.04.009

Thelwall, M.; Levitt, J. M. (2020). Retweeting Covid-19 disability issues: Risks, support and outrage. El profesional de la información, 29 (2), e290216. https://doi.org/10.3145/epi.2020.mar.16

Thelwall, M.; Thelwall, S. (2020). Covid-19 tweeting in English: Gender differences. El profesional de la información, 29 (3), e290301. https://doi. org/10.3145/epi.2020.may.01

Vosoughi, S.; Roy, D.; Aral, S. (2018). The spread of true and false news online. Science, 359 (6380), 1146-1151. content/359/6380/1146

Wang, Y.; McKee, M.; Torbica, A.; Stuckler, D. (2019). Systematic literature review on the spread of healthrelated misinformation on social media. Social Science \& Medicine, 240, 112552. https://doi.org/10.1016/j. socscimed.2019.112552

Wardle, C. (2020). Journalism and the New Information Ecosystem: Responsibilities and Challenges. En: Zimdars, M.; McLeod, K. (eds.). Fake News. Understanding Media and Misinformation in the Digital Age, pp. 71-86. Cambridge, Massachusetts: The MIT Press.

Zarocostas, J. (2020). How to fight an infodemic. The Lancet, 395(10225), 676. https://doi.org/10.1016/ S0140-6736(20)30461-X

Zimdars, M.; McLeod, K. (Eds.) (2020). Fake News. Understanding Media and Misinformation in the Digital Age. Cambridge, Massachusetts: The MIT Press. 


\section{ANEXOS}

Anexo I. Tabla de contingencia entre el País de origen y la Calificación de la desinformación

\begin{tabular}{|c|c|c|c|c|}
\hline \multicolumn{5}{|c|}{ País de origen $*$ Calificación de la desinformación Crosstabulation } \\
\hline & & \multicolumn{3}{|c|}{ Calificación de la desinformación } \\
\hline & & FALSO & VERDADERO & MEDIA VERDAD \\
\hline \multirow{2}{*}{ España } & Count & 240 & 1 & 3 \\
\hline & Std. Residual & 1,5 & $-1,9$ & $-3,9 * * *$ \\
\hline \multirow{2}{*}{ Colombia } & Count & 103 & 10 & 20 \\
\hline & Std. Residual & $-1,4$ & $4,2 * * *$ & $2,6 * *$ \\
\hline \multirow{2}{*}{ Argentina } & Count & 59 & 4 & 7 \\
\hline & Std. Residual &,- 4 & $2,0 *$ &, 4 \\
\hline \multirow{2}{*}{ México } & Count & 73 & 2 & 19 \\
\hline & Std. Residual & $-1,2$ & 0 & $3,9 * * *$ \\
\hline \multirow{2}{*}{ Ecuador } & Count & 69 & 0 & 0 \\
\hline & Std. Residual & 9 & $-1,2$ & $-2,4^{*}$ \\
\hline \multirow{2}{*}{ Brasil } & Count & 61 & 1 & 3 \\
\hline & Std. Residual & 4 &,- 4 & $-1,1$ \\
\hline \multirow{2}{*}{ Venezuela } & Count & 43 & 0 & 5 \\
\hline & Std. Residual & 0 & $-1,0$ & 4 \\
\hline \multirow{2}{*}{ Bolivia } & Count & 43 & 0 & 10 \\
\hline & Std. Residual &,- 6 & $-1,1$ & $2,6 * *$ \\
\hline \multirow{2}{*}{ Costa Rica } & Count & 47 & 0 & 0 \\
\hline & Std. Residual & 8 & $-1,0$ & $-2,0 *$ \\
\hline \multirow{2}{*}{ Perú } & Count & 14 & 1 & 4 \\
\hline & Std. Residual &,- 7 & 9 & 1,9 \\
\hline \multirow{2}{*}{ Chile } & Count & 16 & 0 & 2 \\
\hline & Std. Residual & 0 &,- 6 & 4 \\
\hline \multirow{2}{*}{ Nicaragua } & Count & 17 & 0 & 2 \\
\hline & Std. Residual & 0 &,- 6 &, 3 \\
\hline \multirow{2}{*}{ Guatemala } & Count & 9 & 1 & 2 \\
\hline & Std. Residual &,- 5 & 1,4 & 1,0 \\
\hline \multirow{2}{*}{ Cuba } & Count & 6 & 0 & 0 \\
\hline & Std. Residual &, 3 &,- 4 &,- 7 \\
\hline \multirow{2}{*}{ Paraguay } & Count & 10 & 0 & 0 \\
\hline & Std. Residual & 4 &,- 5 &,- 9 \\
\hline \multirow{2}{*}{ República Dominicana } & Count & 2 & 0 & 1 \\
\hline & Std. Residual &,- 4 &,- 3 & 1,5 \\
\hline \multirow{2}{*}{ Uruguay } & Count & 3 & 0 & 0 \\
\hline & Std. Residual & , 2 &,- 3 &,- 5 \\
\hline
\end{tabular}

${ }^{*} p<0,05 ; * * p<0,01 ; * * * p<0,001$

Chi-Square Tests

\begin{tabular}{|l|c|c|c|}
\hline & Value & df & Asymp. Sig. (2-sided) \\
\hline Pearson Chi-Square & $106,313^{\text {a }}$ & 32 &, 000 \\
\hline Likelihood Ratio & 116,442 & 32 &, 000 \\
\hline Linear-by-Linear Association & 1,570 & 1 &, 210 \\
\hline N of Valid Cases & 913 & & \\
\hline
\end{tabular}

a. 29 cells $(56,9 \%)$ have expected count less than 5 . The minimum expected count is, 07 .

b. Cannot be computed because there is insufficient memory.

c. Cannot be computed because the time limit has been exceeded. 
Anexo II. Tabla de contingencia entre Grupo de País de origen y la Calificación de la desinformación

\begin{tabular}{|l|l|c|c|c|}
\hline \multicolumn{4}{|c|}{ Grupo País * Calificación de la desinformación Crosstabulation } \\
\hline \multicolumn{2}{|c|}{} & \multicolumn{3}{|c|}{ Calificación de la desinformación } \\
\cline { 2 - 5 } & FALSO & VERDADERO & MEDIA VERDAD \\
\hline \multirow{2}{*}{ España } & Count & 240 & 1 & 3 \\
& Std. Residual & 1,5 & $-1,9$ & $-3,9 * * *$ \\
\hline \multirow{2}{*}{ Latinoamérica } & Count & 575 & 19 & 75 \\
& Std. Residual &,- 9 & 1,1 & $2,4 *$ \\
\hline
\end{tabular}

${ }^{*} p<0,05 ; * * p<0,01 ; * * * p<0,001$

\section{Chi-Square Tests}

\begin{tabular}{|l|c|c|c|}
\hline & Value & df & Asymp. Sig. (2-sided) \\
\hline Pearson Chi-Square & $28,755^{\mathrm{a}}$ & 2 &, 000 \\
Likelihood Ratio & 38,666 & 2 &, 000 \\
Linear-by-Linear Association & $27,430^{\mathrm{b}}$ & 1 &, 000 \\
N of Valid Cases & 913 & & \\
\hline
\end{tabular}

a. 0 cells $(, 0 \%)$ have expected count less than 5 . The minimum expected count is 5,35 .

b. The standardized statistic is 5,237 .

Anexo III. Tabla de contingencia entre el Origen y la Calificación de la desinformación

\begin{tabular}{|l|l|c|c|c|}
\hline \multicolumn{4}{|c|}{ Origen de la desinformación * Calificación de la desinformación Crosstabulation } \\
\cline { 3 - 5 } & \multicolumn{3}{|c|}{ Calificación de la desinformación } \\
\cline { 2 - 5 } & FALSO & VERDADERO & MEDIA VERDAD \\
\hline \multirow{2}{*}{ Redes sociales } & Count & 387 & 2 & 40 \\
& Std. Residual &, 1 & $-2,1 *$ &, 6 \\
\hline \multirow{2}{*}{ Mensajería } & Count & 207 & 2 & 8 \\
\hline \multirow{2}{*}{ Medios } & Std. Residual &, 9 & $-1,0$ & $-2,4 *$ \\
\hline \multirow{2}{*}{ Otros } & Count & 38 & 7 & 6 \\
& Std. Residual & $-1,1$ & $6,3 * * *$ & 11 \\
\hline
\end{tabular}

${ }^{*} p<0,05 ; * * p<0,01 ; * * * p<0,001$

Chi-Square Tests

\begin{tabular}{|l|c|c|c|}
\hline & Value & df & Asymp. Sig. (2-sided) \\
\hline Pearson Chi-Square & $89,688^{\mathrm{a}}$ & 10 &, 000 \\
Likelihood Ratio & 57,751 & 10 &, 000 \\
Linear-by-Linear Association & $10,217^{\mathrm{c}}$ & 1 &, 001 \\
N of Valid Cases & 878 & & \\
\hline
\end{tabular}

a. 8 cells $(44,4 \%)$ have expected count less than 5 . The minimum expected count is, 46 .

b. Cannot be computed because there is insufficient memory.

c. The standardized statistic is 3,196 . 
Anexo IV. Tabla de contingencia entre el Tipo y la Calificación de la desinformación

\begin{tabular}{|c|c|c|c|c|}
\hline \multicolumn{5}{|c|}{ Tipo de desinformación * Calificación de la desinformación Crosstabulation } \\
\hline & & \multicolumn{3}{|c|}{ Calificación de la desinformación } \\
\hline & & FALSO & VERDADERO & MEDIA VERDAD \\
\hline \multirow{2}{*}{ Otros } & Count & 205 & 4 & 12 \\
\hline & Std. Residual & 6 &,- 5 & $-1,6$ \\
\hline \multirow{2}{*}{ Medidas } & Count & 146 & 3 & 10 \\
\hline & Std. Residual & ,3 &,- 3 & $-1,0$ \\
\hline \multirow{2}{*}{ Situación de un país } & Count & 127 & 8 & 22 \\
\hline & Std. Residual & $-1,1$ & $2,4 *$ & $2,4^{*}$ \\
\hline \multirow{2}{*}{ Curas } & Count & 93 & 2 & 14 \\
\hline & Std. Residual &,- 4 &,- 3 & 1,6 \\
\hline \multirow{2}{*}{ Prevención } & Count & 69 & 1 & 2 \\
\hline & Std. Residual & 6 &,- 5 & $-1,7$ \\
\hline \multirow{2}{*}{ Contagios } & Count & 51 & 0 & 3 \\
\hline & Std. Residual & 4 & $-1,1$ &,- 7 \\
\hline \multirow{2}{*}{ Origen del virus } & Count & 54 & 1 & 2 \\
\hline & Std. Residual &, 4 &,- 3 & $-1,3$ \\
\hline \multirow{2}{*}{ Características del virus } & Count & 15 & 1 & 7 \\
\hline & Std. Residual & $-1,2$ &, 7 & $3,6 * * *$ \\
\hline \multirow{2}{*}{ Síntomas } & Count & 9 & 0 & 2 \\
\hline & Std. Residual &,- 3 &,- 5 & 1,1 \\
\hline \multirow{2}{*}{ Curas-Prevención } & Count & 18 & 0 & 1 \\
\hline & Std. Residual &, 3 &,- 7 &,- 5 \\
\hline
\end{tabular}

${ }^{*} p<0,05 ;{ }^{* *} p<0,01 ;{ }^{* *} p<0,001$

Chi-Square Tests

\begin{tabular}{|l|c|c|c|}
\hline & Value & df & Asymp. Sig. (2-sided) \\
\hline Pearson Chi-Square & $43,602^{\mathrm{a}}$ & 18 &, 001 \\
Likelihood Ratio & 39,445 & 18 &, 002 \\
Linear-by-Linear Association & 1,256 & 1 &, 262 \\
N of Valid Cases & 882 & & \\
\hline
\end{tabular}

a. 14 cells $(46,7 \%)$ have expected count less than 5 . The minimum expected count is ,25.

b. Cannot be computed because there is insufficient memory.

c. Cannot be computed because the time limit has been exceeded. 
Anexo V. Tabla de contingencia entre el Formato de la desinformación y el País de origen

\begin{tabular}{|c|c|c|c|c|c|c|c|c|c|c|c|c|}
\hline \multicolumn{13}{|c|}{ Formato de la desinformación * País de origen Crosstabulation } \\
\hline & & España & Colombia & Argentina & México & Ecuador & Brasil & Venezuela & Bolivia & $\begin{array}{l}\text { Costa } \\
\text { Rica }\end{array}$ & Perú & Chile \\
\hline \multirow{2}{*}{ Texto } & Count & 137 & 59 & 29 & 40 & 33 & 39 & 33 & 18 & 22 & 5 & 9 \\
\hline & Std. Residual & , 7 &,- 6 & $-1,0$ &,- 7 &, 5 & 1,3 & $2,3 *$ & $-1,7$ & 0 & $-1,9$ &, 7 \\
\hline \multirow{2}{*}{ Video } & Count & 48 & 19 & 14 & 25 & 6 & 10 & 4 & 13 & 3 & 2 & 5 \\
\hline & Std. Residual &, 4 &,- 7 &, 5 & $2,4 *$ & $-1,4$ &,- 3 & $-1,4$ & 1,2 & $-1,7$ & $-1,0$ & 1,6 \\
\hline \multirow{2}{*}{$\begin{array}{l}\text { Texto- } \\
\text { Imagen }\end{array}$} & Count & 27 & 26 & 8 & 16 & 17 & 9 & 1 & 15 & 6 & 0 & 1 \\
\hline & Std. Residual & $-1,8$ & 1,6 &,- 7 & 8 & $2,7 * *$ &,- 1 & $-2,2 *$ & $2,5^{*}$ &,- 2 & $-1,8$ &,- 8 \\
\hline \multirow{2}{*}{ Imagen } & Count & 36 & 20 & 11 & 4 & 1 & 9 & 2 & 3 & 7 & 0 & 0 \\
\hline & Std. Residual & 1,4 & 1,6 & 1,2 & $-1,8$ & $-2,2 *$ & 8 & $-1,3$ & $-1,2$ & 1,0 & $-1,6$ & $-1,2$ \\
\hline \multirow{2}{*}{ Audio } & Count & 16 & 9 & 8 & 4 & 3 & 0 & 2 & 2 & 4 & 7 & 0 \\
\hline & Std. Residual &,- 2 & ,2 & 1,6 &,- 7 &,- 5 & $-2,0 *$ &,- 5 &,- 8 & ,7 & $4,5 * * *$ & $-1,0$ \\
\hline \multirow{2}{*}{ Otros } & Count & 9 & 2 & 4 & 5 & 4 & 0 & 5 & 5 & 4 & 10 & 0 \\
\hline & Std. Residual & $-1,5$ & $-1,9$ & 0 & 0 & ,3 & $-1,9$ & 1,6 & 1,2 & 1,0 & $7,7 * * *$ &,- 9 \\
\hline
\end{tabular}

$* p<0,05 ; * * p<0,01 ; * * * p<0,001$

Chi-Square Tests

\begin{tabular}{|l|r|r|r|}
\hline & Value & df & Asymp. Sig. (2-sided) \\
\hline Pearson Chi-Square & $191,672^{\mathrm{a}}$ & 50 &, 000 \\
Likelihood Ratio & 168,516 & 50 &, 000 \\
Linear-by-Linear Association & 4,349 & 1 &, 037 \\
N of Valid Cases & 895 & & \\
\hline
\end{tabular}

a. 24 cells $(36,4 \%)$ have expected count less than 5 . The minimum expected count is, 80 .

b. Cannot be computed because there is insufficient memory. 